\title{
Phosphatidylinositol 3-kinase (PI3K) inhibitors as cancer therapeutics
}

\author{
Akintunde Akinleye ${ }^{1}$, Parthu Avvaru', Muhammad Furqan ${ }^{1}$, Yongping Song ${ }^{2}$ and Delong Liu 1,2*
}

\begin{abstract}
Phosphatidylinositol 3-kinases (PI3Ks) are lipid kinases that regulate diverse cellular processes including proliferation, adhesion, survival, and motility. Dysregulated PI3K pathway signaling occurs in one-third of human tumors. Aberrantly activated PI3K signaling also confers sensitivity and resistance to conventional therapies. PI3K has been recognized as an attractive molecular target for novel anti-cancer molecules. In the last few years, several classes of potent and selective small molecule PI3K inhibitors have been developed, and at least fifteen compounds have progressed into clinical trials as new anticancer drugs. Among these, idelalisib has advanced to phase III trials in patients with advanced indolent non-Hodgkin's lymphoma and mantle cell lymphoma. In this review, we summarized the major molecules of PI3K signaling pathway, and discussed the preclinical models and clinical trials of potent small-molecule PI3K inhibitors.
\end{abstract}

\section{Introduction}

Phosphatidylinositol 3-kinases (PI3Ks) are lipid kinases that play central role in regulation of cell cycle, apoptosis, DNA repair, senescence, angiogenesis, cellular metabolism, and motility [1]. They act as intermediate signaling molecules and are most well known for their roles in the PI3K/AKT/mTOR signaling pathway [2,3]. PI3Ks transmit signals from the cell surface to the cytoplasm by generating second messengers - phosphorylated phosphatidylinositols - which in turn activate multiple effector kinase pathways, including BTK, AKT, PKC, NF-kappa-B, and JNK/SAPK pathways, and ultimately result in survival and growth of normal cells [1-5] (Figure 1). Although the activity of PI3Ks is tightly regulated in normal cells by internal signals such as PTEN (phosphatase and tensin homolog deleted from chromosome 10), it has been recognized that deregulation of the PI3K signaling pathway is associated with development in one-third of human cancers [6-9]. Aberrantly activated PI3K pathway promotes carcinogenesis and tumor angiogenesis [3,10-12]. For example, approximately $30 \%$ of breast cancers demonstrated activating missense mutations of PIK3CA, the gene encoding the catalytic p110 $\alpha$ subunit of class I PI3K, and the mutated gene provides cells with a growth advantage

\footnotetext{
* Correspondence: DELONG_LIU@NYMC.EDU

'Division of Hematology/Oncology, Department of Medicine, New York Medical College and Westchester Medical Center, Valhalla, NY 10595, USA ${ }^{2}$ Henan Cancer Hospital, Zhengzhou University, Zhengzhou, China
}

and promotes tumorigenesis [13]. In addition, dysregulated PI3K pathway signaling has been implicated in conferring resistance to conventional therapies including biologics, hormonal therapy, tyrosine kinase inhibitors, radiation, and cytotoxics in breast cancer, glioblastoma, and non-small cell lung cancer $[2,14]$. Other genetic aberrations that drive the PI3K pathway in cancer include gene amplification of PI3Ks, loss of the regulatory activity of PTEN, and activating mutations of receptor tyrosine kinases (RTKs) such as EGFR and HER2 [13,15-18]. With this background, PI3K has become recognized within the last decade as a viable target for novel anti-cancer therapy. Successful drug design has yielded several classes of potent, selective, and efficacious small molecule PI3K inhibitors that are currently at different stages of development. Idelalisib, which represents the first-in-class oral PI3K p110- $\delta$ inhibitor, was efficacious with an acceptable safety and tolerability profile in early phase studies, and has progressed into phase III clinical trials in patients with advanced indolent non-Hodgkin's lymphoma (iNHL), chronic lymphocytic leukemia (CLL) and mantle cell lymphoma (MCL) [19-23]. In this comprehensive review, we provide an overview of the PI3K signaling pathway in tumorigenesis and highlight recent advances in the design of small-molecule inhibitors of PI3K as novel anti-cancer therapies. In addition, this review discusses the most recent preclinical and clinical studies of inhibitors targeting the different isoforms of the 


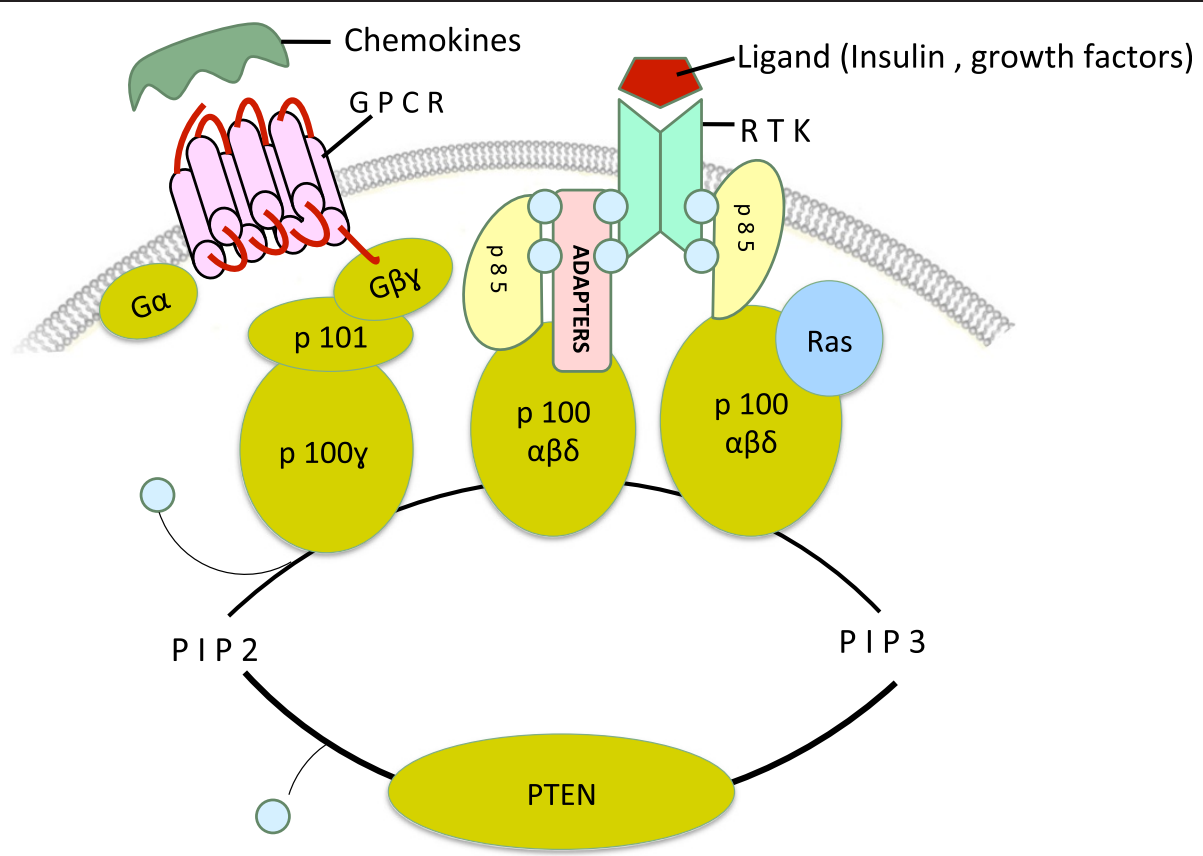

Figure 1 The class I PI3K family. Class I PI3Ks are heterodimeric proteins and comprised of a catalytic p110 subunit complexed with a regulatory $p 85$ or $p 101$ subunit. The catalytic p110 subunit exists in four isoforms $(\alpha, \beta, \delta$, and $\gamma)$, whereas the regulatory p85 subunit in three isoforms - p85, p55, and p50. Their corresponding upstream receptors and adaptor proteins are also indicated. RTK: receptor tyrosine kinase; GPCR: G-protein coupled receptors.

PI3K enzymes in the treatment of hematological and solid malignancies.

\section{PI3K signaling pathway in health and tumorigenesis}

PI3Ks represent a family of lipid kinases that lie upstream of complex, intricate, interconnected intracellular signaling networks [1] (Figure 2). They transduce signals from transmembrane receptors such as RTKs and G-protein coupled receptors (GPCRs) to the cytoplasm - through production of phosphorylated lipids - to regulate key cellular processes including proliferation, differentiation, senescence, motility, and survival [13].

PI3Ks are enzymes of approximately $200-300 \mathrm{kDa}$ in molecular weight (Figure 3). In human, three distinct classes of PI3Ks (I - III) have been identified (Table 1). They differ on basis of their structural characteristics, substrate specificities, and nature of lipid end-products. Class I PI3Ks are heterodimers and further divided into 2 subfamilies, IA and IB. Class IA PI3Ks are the most studied and frequently implicated in cancer [24,25]. Structurally, class IA PI3Ks comprise of catalytic p110 complexed with regulatory $\mathrm{p} 85$ subunits. The catalytic p110 isoforms $(\alpha, \beta$, and $\delta)$ are encoded by the genes PIK3CA, PIK3CB, and $P I K 3 C D$ respectively, whereas the regulatory p 85 subunit- p85, p55, and p50 isoforms - are encoded by PIK3R1, PIK3R2, and PIK3R3 genes, respectively [26,27]. Class IB PI3Ks also consist of catalytic p110y and regulatory p101, and p84/p87PIKAP subunits [27]. Likewise, class III PI3Ks are heterodimeric proteins having a catalytic (hVps34) subunit associated with regulatory (p150) subunit. The regulatory subunit subserves 2 functions [28]. Upon receptor activation, it recruits the catalytic subunit to tyrosine phosphorylated proteins (RTKs, adaptors) at the plasma membrane where the catalytic subunit phosphorylates its lipid substrates [27]. In addition, the enzymatic activity of the catalytic subunit is constitutively inhibited by the regulatory subunit in quiescent cells [28]. Class II PI3K enzymes also exist in 3 isoforms (PI3KC2 $\alpha$, PI3KC2 $\beta$ and PI3KC2 $\gamma$ ). However, these are monomers with high molecular weight, lack regulatory subunits, and possess single catalytic unit that directly interacts with phosphorylated adapter proteins $[26,29]$. The catalytic units of PI3Ks possess an N-terminal sequence, a central region, and a C-terminus; however the modular organizations are distinctive. The $\mathrm{N}$-terminus of class IA p110 ( $\alpha, \beta$, and $\delta)$ enzymes harbors the p85- binding domain (PI3K-ABD), which constitutively interacts with the $\mathrm{SH} 2$ domain of the regulatory subunit, and also houses the Ras-binding domain (PI3K-RBD) which mediates interaction with Ras-GTPases. The central region is comprised of the C2 PI3K-type and PIK helical domains, whereas the Cterminus contains the catalytic apparatus (PI3K/PI4K kinase domain). The PI3K-RBD domain is the most divergent region of the class IA enzymes [25]. The class IB 


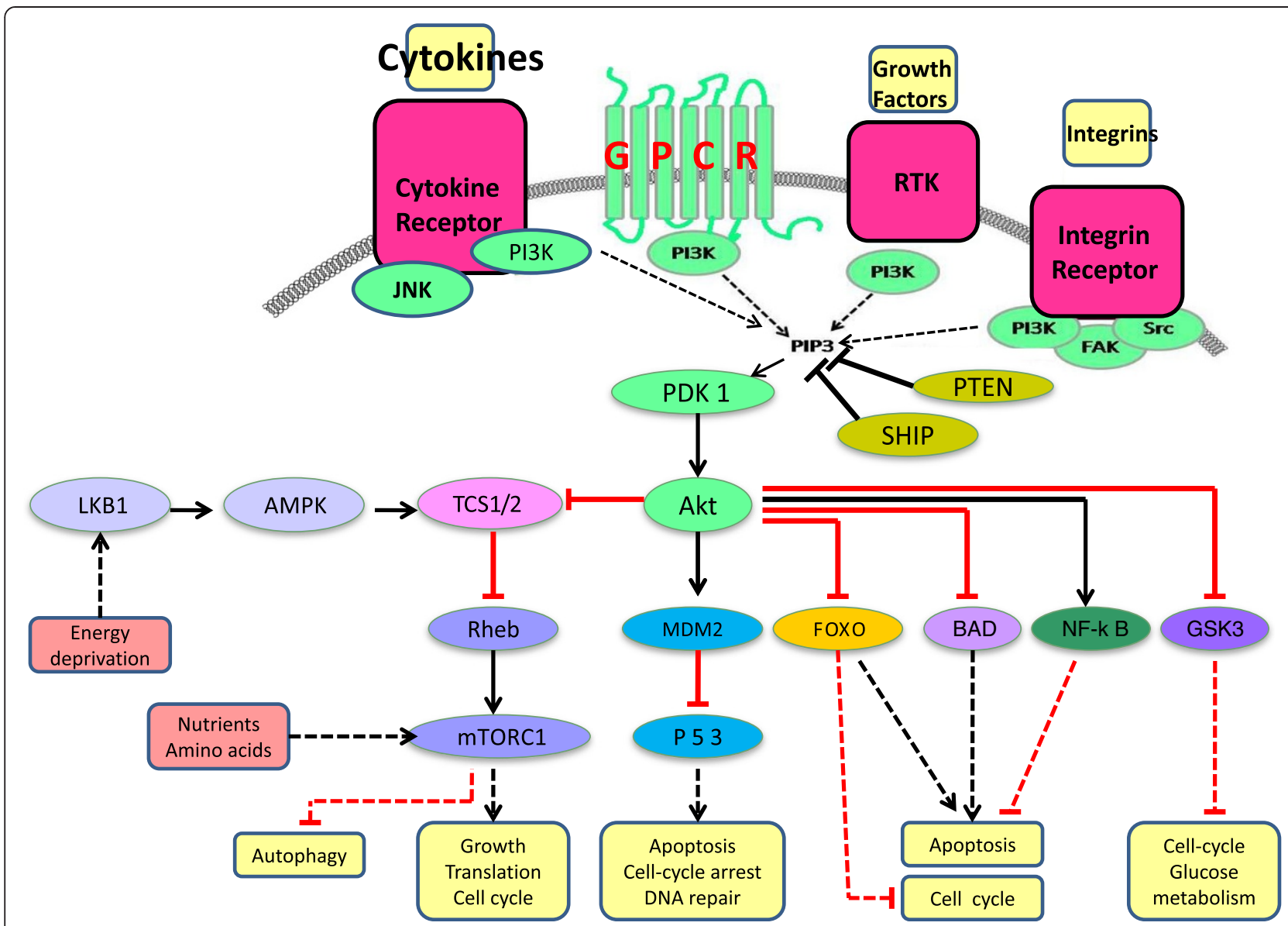

Figure 2 Schematic representation of the PI3K signaling pathway. Four major extracellular signals, growth factors, cytokines, hormones/ chemokines, and integrins, activate PI3K, which transmit the signals through appropriate pathways to control diverse cellular processes, including cell cycle, apoptosis, DNA repair, senescence, angiogenesis, cellular metabolism, autophagy, and motility. The multiple effector kinase pathways activated by PI3K are highlighted in the figure.

enzyme, p110 $\gamma$, is similar in structural organization to the class IA p110 proteins but also contains a putative $\mathrm{N}$-terminus PH domain [30]. In class II enzymes, however, the central region is made-up of four domains (PI3K-RBD, C2 PI3K-type, PIK helical, PI3K/PI4K kinase), and the
C-terminal sequence composed of the $\mathrm{C} 2$, and PX domains. The N-termini of class II PI3Ks are more distantly related. This region contains the binding site for GRB2 (Growth factor receptor-bound protein 2), an adapter protein that often complexes with SOS and Ras-GTPases, and facilitates

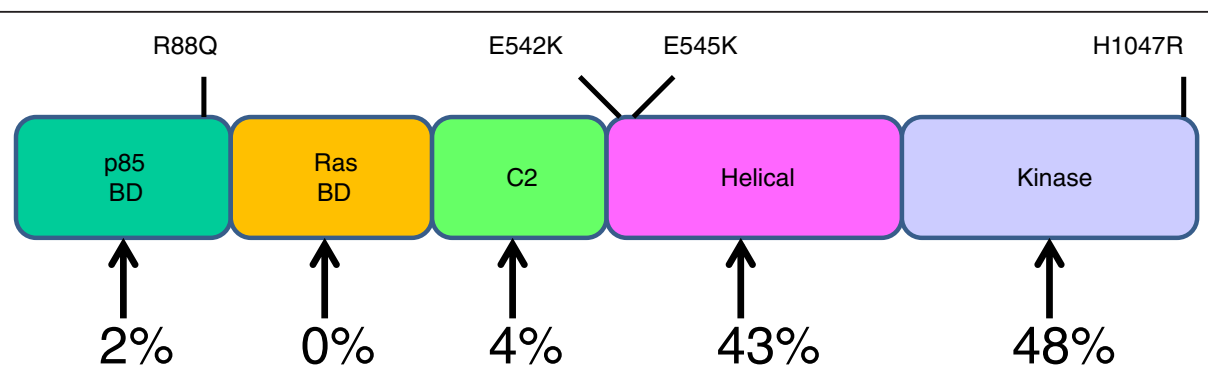

Figure 3 The structural organization of p110-a enzyme. The catalytic subunit (p110-a) of PI3Ks possesses a central region flanked by the Nand $\mathrm{C}$-terminus of varying lengths with distinctive modular organization. The N-terminus of p110-a enzyme harbors the p85-binding domain (PI3K-ABD) and the Ras-binding domain (PI3K-RBD) which mediates interaction with the regulatory p85 and the Ras-GTPases respectively. The central region is composed of the C2 PI3K-type and PIK helical domains, whereas the C-terminus houses the enzymatic apparatus (PI3K/PI4K kinase domain). Common cancer-associated mutations within each domain of the enzyme is indicated. 
Table 1 Phosphatidylinositol-3 kinase genes and proteins

\begin{tabular}{|c|c|c|c|c|c|}
\hline Class & Gene & Chromosomal location & Protein & Mass (kDa) & Sequence length (AA) \\
\hline \multicolumn{6}{|l|}{ Class I } \\
\hline \multirow[t]{6}{*}{ IA } & PIK3CA & $3 q 26.3$ & p110-a & 124.28 & 1068 \\
\hline & $P I K 3 C B$ & $3 q 22.3$ & p110- $\beta$ & 122.76 & 1070 \\
\hline & PIK3CD & $1 p 36.2$ & p110- $\delta$ & 119.48 & 1044 \\
\hline & PIK3R1 & $5 q 13.1$ & $\mathrm{p} 85-\mathrm{a}$ & 83.60 & 724 \\
\hline & PIK3R2 & 19p13.1 & $p 85-\beta$ & 81.55 & 728 \\
\hline & PIK3R3 & $1 \mathrm{p} 34.1$ & $p 55-\gamma$ & 54.45 & 461 \\
\hline \multicolumn{6}{|l|}{ IB } \\
\hline & PIK3CG & $7 q 22.3$ & $\pi 110-\gamma$ & 126.45 & 1102 \\
\hline & PIK3R5 & 17p13.1 & p101 & 97.35 & 880 \\
\hline & PIK3R6 & 17p13.1 & p84/p87PIKAP & 84.26 & 754 \\
\hline \multicolumn{6}{|l|}{ Class II } \\
\hline & PIK3C2A & $11 p 15.1$ & PIK-C2a & 190.68 & 1686 \\
\hline & PIK3C2B & $1 \mathrm{q} 32.1$ & PIK-C2 $\beta$ & 184.77 & 1634 \\
\hline & PIK3C2G & $12 \mathrm{p} 12.3$ & PIK-C2Y & 165.72 & 1445 \\
\hline \multicolumn{6}{|c|}{ Class III } \\
\hline & PIK3C3 & $18 q 12.3$ & hVps34 & 101.55 & 887 \\
\hline & PIK3R4 & $3 q 22.1$ & p150 & 153.10 & 1358 \\
\hline
\end{tabular}

Abbreviations: $A A$ amino acids; $k D a$ kilodalton.

recruitment and activation of PI3KC $2 \alpha$ and $\mathrm{PI} 3 \mathrm{KC} 2 \beta$ by activated growth factor receptors [31]. In addition, the $\mathrm{N}$-terminal sequence of PI3KC2 $\alpha$ also serves as major binding site for clathrin trimers and thereby independently modulating clathrin distribution and function [32,33]. Class III catalytic enzyme, hVps34, is characterized by an $\mathrm{N}$-terminal C2 PI3K-type domain, a centrally located PIK helical domain, and a C-terminus PI3K/PI4K kinase domain [34].

P110 $\alpha$ and p100 $\beta$ are ubiquitously expressed in all tissues, whereas p1108 is mostly confined to hematopoietic cells, where it plays an important role in B-cell homeostasis and functioning. These enzymes integrate inputs from activated RTKs and GPCRs [25]. The p110y, predominantly expressed by pancreas, skeletal muscles, liver and heart, mediates signaling downstream of GPCRs [30]. Class II PI3Ks are widely expressed at varying levels in all tissues, and activated by RTKs, cytokine receptors, chemokine receptors, and integrins [31,32]. Similarly, hVps34 is ubiquitously expressed, with the highest expression in skeletal muscle, and plays a key role in diverse intracellular trafficking in the cytosolic compartment of the cells [35].

PI3Ks are predominantly cytosolic, non-phosphorylated and catalytically inactive in quiescent cells except class II PI3Ks which preferentially associate with membrane fraction of cells [32]. In response to growth factor stimulation, tyrosine phosphate motifs of activated receptors recruit PI3Ks to the plasma membrane by direct interaction with the SH2 domains of the regulatory subunit [36]. This interaction also alters the conformation of the regulatory subunit, abrogates its inhibitory activity, and causes full activation of the enzymatic activity of the catalytic subunit [28]. PI3Ks can also be stimulated by activated Ras-GTPases that exist in a complex with phosphorylated adapter proteins (GRB2, SOS) $[8,26,31]$. These activated PI3Ks then catalyze the generation of second messengers - phosphorylated phosphatidylinositols (PI) - which in turn activate multiple downstream signaling pathways [1]. In vitro, class I PI3Ks are capable of phosphorylating PI to PI 3-phosphate; PI 4-phosphate to PI 3,4-bisphosphate; and PI 4,5-bisphosphate to PI 3,4,5-trisphosphate. However PI 4,5-bisphosphate (PIP2) is the preferred lipid substrate in vivo [27]. hVps34, the class III PI3K enzyme, mainly catalyzes the conversion of PI to PI 3-phosphate to mediate cellular trafficking processes [27,34], while class II enzymes utilize PI, PIP2, and PI 4-phosphate as substrates to generate PIP3 and PI 3,4-bisphosphate in vivo [32,37-39].

PI3K signaling regulates a wide range of cellular processes including protein synthesis, cell survival, proliferation, differentiation, senescence, motility, angiogenesis and metabolism. Upon generation of second messengers (PIP3, PI 3,4-bisphosphate), the PI3K signaling impinges on a diverse array of pleckstrin homology $(\mathrm{PH})$ domain-containing intracellular signaling proteins, and indirectly triggers a cascade of events that culminates in activation of multiple 
effector kinase pathways, including the mTOR, ERK1/2, p38 MAPK, NF-kappa-B, and JNK/SAPK pathways $[1,40,41]$. These signaling proteins include serine-threonine kinases (AKT and PDK1), protein tyrosine kinases (Tec/ BTK family), exchange factors for GTP-binding proteins (Grp1 and Rac exchange factors), cytoskeletal proteins, and adapter proteins $(\mathrm{GAB}-1)$ [4,27]. Of note, $\mathrm{PIP}_{3}$ binds to the $\mathrm{PH}$ domains of AKT and PDK1, recruits both molecules to the plasma membrane in close proximity where AKT is activated by phosphorylation at Tyr-308 by PDK1 [42-44]. PI3K-AKT signaling pathway promotes cell growth and survival by several mechanisms. Recent studies suggest that activated AKT has direct effect on the apoptosis pathway by targeting and downregulating the pro-apoptotic activity of Bcl-2 family members BAD and BAX resulting in cell survival [1]. Furthermore, PI3K-AKT signaling controls cell death and survival through NF-kappa-B regulation of pro- and anti-apoptotic genes [45]. AKT also signals to a few other proteins, such as mammalian target of rapamycin (mTOR) -containing protein complex mTORC1, GSK3 (glycogen synthase kinase 3), TSC (tuberous sclerosis complex), and FOXOs (the forkhead family of transcription factors), and thereby regulates cell proliferation, protein synthesis and glucose metabolism [46-48]. Besides the PI3K-AKT pathway, several other pathways, such as those of BTK/Tec kinases, have also recently been characterized [4]. The PI3K-BTK signaling plays an essential role in orderly B-cell development, proliferation and survival through recruitment and activation by CD19 $[49,50]$. In response to CD28 costimulation, PI3K upregulates BCL-XL expression in T-cells, and confers resistance to apoptosis during their activation [51]. In addition to its pro-survival and growth-promoting roles, the PI3K pathway is essential in endothelial cell migration during angiogenesis through VEGF-A signaling [52,53], required for lymphatic vasculature development via signaling by EGF and FGF2, and also participates in cardiomyogenesis from embryonic stem cells [54].

The lipid end-products of PI3Ks are barely detectable in unstimulated cells. The cellular levels of the second messengers are tightly regulated by the opposing action of at least three different types of phosphatases. PTEN can reduce the cellular pool of PIP3 by converting PIP3 back to inactive PIP2 through dephosphorylation at the D3 position, whereas the Src-homology 2 (SH2)-containing phosphatases (SHIP1 and SHIP2) specifically hydrolyze the D5 phosphate group of PIP3 to produce PI 3,4-bisphosphate [55]. The activity of SHIP1 and SHIP2 only partially downregulate PI3K signaling as PI 3,4-bisphosphate can also mediate PI3K-dependent responses independent of those stimulated by PIP3 [1]. Full termination of PI3K signaling is carried out by the concerted actions of inositol polyphosphate 4-phosphatase type II (INPP4B) and myotubularin, which preferentially hydrolyze PI 3,4-bisphosphate to PI 3-phosphate, and PI 3-phosphate to PI respectively [56-58].

Given its pivotal role in preventing apoptosis and stimulating proliferation in normal cells, it is not surprising that the PI3K signaling pathway is dysregulated frequently in human cancers, and exploited by tumor cells for increased proliferative potential, evasion of apoptosis, tissue invasion, and metastasis [3,27]. The PI3K signaling is aberrantly activated by at least three major mechanisms including activating mutations or amplification of catalytic subunits of PI3Ks, inactivation of the lipid phosphatase PTEN, and receptor amplification or mutations (RTKs, GPCR $[12,16]$. For instance, approximately $30 \%$ of breast cancers are associated with activating missense mutations of PIK3CA, the gene encoding the catalytic $\mathrm{p} 110 \alpha$ subunit of class IA PI3K, which provides cells with a growth advantage and promotes tumor progression [13]. Somatic loss of PTEN activity by gene mutation, epigenetic silencing or deletion is associated with significantly greater Gleason score, poorer prognosis, and higher rate of metastasis in prostate cancer $[59,60]$. Increased p110 $\beta$ activity due to gene amplification is frequent in human colon cancer (70\%), and confers limitless growth potential [61]. Recent cancer genomic analysis showed that PIK3R1, the gene encoding the $\mathrm{p} 85 \alpha$ regulatory subunit, was mutated in up to $10 \%$ of human glioblastomas [62].

PI3Ks have therefore emerged as viable targets for novel anti-cancer therapy. Successful drug design has yielded three classes of potent and selective small molecule inhibitors that have progressed from advanced preclinical testing to different stages of clinical development. Idelalisib, which represents the first-in-class oral PI3K p110- $\delta$ inhibitor, demonstrated high efficacy and a good safety profile in early phase studies. It has progressed into phase III clinical trials in patients with advanced indolent non-Hodgkin's lymphoma (iNHL) and mantle cell lymphoma (MCL) [19-23,63].

\section{PI3K inhibitors in clinical development}

PI3K inhibitors are divided into three classes, pan-class I, isoform-selective and dual PI3K/mTOR inhibitors, based on pharmacokinetic properties and isoform selectivity for the ATP binding site of PI3Ks [64,65] (Table 2). In the pan-class I PI3K inhibitors, wortmannin and LY294002 represent the first generation inhibitors with highly potent PI3K-inhibitory property. Notably, wortmannin and LY294002 inhibit PI3Ks activity in vitro at IC50 of $1 \mathrm{nM}$ and 1.4 uM, respectively [66-68]. However, these compounds demonstrated considerable toxicities in animal studies and were not advanced to clinical evaluation because of this pharmaceutical limitation $[69,70]$. Nonetheless, at least 15 agents are in various stages of clinical development, with favorable safety, efficacy, pharmacokinetics, and pharmacodynamics profiles. GDC-0941 was first 
Table 2 PI3K inhibitors in clinical trials

\begin{tabular}{|c|c|c|c|c|c|}
\hline Drug & Target(s) & Tumors & Toxicities & Clinical trials & References \\
\hline Idelalisib (CAL-101) & $\mathrm{p} 110-\delta$ & $\mathrm{CLL} / \mathrm{SLL}, \mathrm{iNHL}, \mathrm{MCL}$ & $\begin{array}{l}\text { Pyrexia, nausea, decrease } \\
\text { appetite, fatigue }\end{array}$ & III & {$[76,77,80,83,86,88-90]$} \\
\hline Buparlisib (BKM-120) & $p 110-a,-\beta,-\delta,-\gamma$ & Breast, GBM, NSCLC & $\begin{array}{l}\text { Rash, hyperglycemia diarrhea, } \\
\text { anorexia }\end{array}$ & $\mid \mathrm{B} / \mathrm{I}$ & [103-109] \\
\hline GDC-0941 & $p 110-a,-\beta,-\delta,-\gamma$ & $\begin{array}{l}\text { Breast, NSCLC, melanoma } \\
\text { endometrial, pancreatic }\end{array}$ & $\begin{array}{l}\text { Nausea, diarrhea, rash } \\
\text { vomiting, anorexia }\end{array}$ & $\mid \mathrm{B} / \mathrm{I}$ & [117-123] \\
\hline PX-866 & p110-a,- $\beta,-\delta,-\gamma$ & $\begin{array}{l}\text { Ovarian, prostate, } \\
\text { GBM NSCLC }\end{array}$ & $\begin{array}{l}\text { Fatigue, diarrhea } \\
\text { thromboembolism }\end{array}$ & $\|$ & [126-129] \\
\hline GDC-0032 & $p 110-\alpha,-\delta,-\gamma$ & Breast, NSCLC & $\begin{array}{l}\text { Diarrhea, hyperglycemia fatigue, } \\
\text { nausea, decreased appetite }\end{array}$ & । & [132] \\
\hline BAY 80-6946 & p110- $a,-\beta$ & $\begin{array}{l}\mathrm{NHL} \text {, esophageal, } \\
\text { sarcoma pancreatic }\end{array}$ & $\begin{array}{l}\text { Alopecia, dysgeusia } \\
\text { anemia, mucositis }\end{array}$ & । & [135-137] \\
\hline $\mathrm{IPI}-145$ & p110- $\delta,-\gamma$ & CLL/SLL, iNHL, MCL & $\begin{array}{c}\text { Cytopenias liver enzyme } \\
\text { elevations }\end{array}$ & I & {$[138,139]$} \\
\hline BEZ-235 & p110- $a,-\beta,-\delta,-\gamma /$ mTOR & Breast, GBM & Mucositis & $\mid \mathrm{B} / \mathrm{I}$ & [149-152] \\
\hline BYL-719 & p110-a & $\begin{array}{l}\text { Breast, cervical, } \\
\text { endometrial ovarian, } \mathrm{H} \& \mathrm{~N}\end{array}$ & $\begin{array}{c}\text { Nausea, diarrhea } \\
\text { hyperglycemia, vomiting }\end{array}$ & $\mid \mathrm{B} / \mathrm{I}$ & [153-155] \\
\hline BGT-226 & p110- $a,-\beta,-\delta,-\gamma /$ mTOR & Solid tumors, breast & Nausea, vomiting diarrhea & $1 / 1 \mid$ & {$[156]$} \\
\hline PF-04691502 & p110- $a,-\beta,-\delta,-\gamma /$ mTOR & Endometrial & $\begin{array}{l}\text { Fatigue, nausea, vomiting } \\
\text { decreased appetite, rash }\end{array}$ & $\|$ & [162] \\
\hline GDC-0980 & p110- $a_{,}-\beta,-\delta,-\gamma /$ mTOR & Prostate & Hyperglycemia, rash mucositis & $\mid \mathrm{B} / \mathrm{I}$ & {$[167,168]$} \\
\hline GSK-2126458 & $\mathrm{p} 110-\mathrm{a},-\beta,-\delta,-\gamma / \mathrm{mTOR}$ & RCC, bladder & Nausea, vomiting diarrhea & । & {$[169,170]$} \\
\hline PF-05212384 & p110-a,-y/mTOR & Solid tumor, CRC & $\begin{array}{c}\text { Rash, mucositis transaminitis, } \\
\text { hyperglycemia }\end{array}$ & $\|$ & {$[172]$} \\
\hline$X L-765$ & p110- $a,-\beta,-\delta,-\gamma /$ mTOR & NSCLC, gliomas & $\begin{array}{l}\text { Nausea, diarrhea elevated } \\
\text { liver enzymes }\end{array}$ & $\mid \mathrm{B} / \mathrm{I}$ & [176-178] \\
\hline$X L-147$ & $p 110-\alpha,-\beta,-\delta,-\gamma$ & Solid tumor, GBM & Nausea, vomiting diarrhea & $|/| \mid$ & [180-183] \\
\hline
\end{tabular}

Abbreviations: CLL/SLL chronic lymphocytic leukemia/small lymphocytic leukemia; CRC colorectal cancer; GBM glioblastoma multiforme; $H \& N$ head and neck cancer iNHL indolent non-Hodgkin's lymphoma; MCL mantle cell lymphoma; NHL non-Hodgkin's lymphoma; NSCLC non-small cell lung cancer; RCC renal cell cancer.

to enter clinical trials but idelalisib is now the most advanced.

\section{Idelalisib (CAL-101, GS-1101)}

Idelalisib (formerly CAL-101, GS-1101) is an oral, firstin-class, highly selective inhibitor of PI3K p $110-\delta$ isoform that was identified in a kinome-wide screen using purified enzymes [19,71]. A phenylquinazolin derivative, idelalisib demonstrated 240 - to 2500 -fold selectivity for p110 $\delta$ over the other class I PI3K isoforms in cell-based assays [71], exerted far greater pro-apoptotic activity in B-ALL and CLL cell lines compared with AML cells in a dose- and time-dependent fashion [71,72], and inhibited CLL cell chemotaxis toward CXCL12 and CXCL13 [73]. The compound also suppresses survival signals provided by the microenvironment in CLL cell lines [71]. Treatment with idelalisib induces cell cycle arrest and apoptosis in Hodgkin's lymphoma cell lines [74]. In addition, idelalisib demonstrated cytotoxicity against LB and INA-6 myeloma cell lines [75]. Importantly, idelalisib does not increase apoptosis in normal T / NK cells, nor does it block antibody-dependent cellular cytotoxicity, but the inhibitor can decrease the level of various inflammatory and antiapoptotic cytokines from activated $T$ cells [72]. These studies provided strong rationale for clinical trials of idelalisib as a targeted therapy for B-cell lymphoproliferative disorders.

It was reported that single agent idelalisib at doses of 50-350 mg BID demonstrated acceptable toxicity profile, positive pharmacodynamic effects, and favorable clinical activity in heavily pretreated patients with relapsed/refractory CLL, including those with adverse cytogenetics [76,77]. The final results of this phase I trial, presented at the 2013 American Society of Clinical Oncology (ASCO) meeting, showed an impressive $56 \%$ overall response rate (ORR), 17 months median progression free survival (PFS), and 18 months median duration of response (DOR) in patients treated with idelalisib alone [20]. Clearly, this study demonstrated that the activity of single-agent idelalisib in relapsed/refractory CLL is superior to current standard therapies [78,79]. Serious adverse events of pneumonia, neutropenia, thrombocytopenia, neutropenic fever, anemia, and ALT/AST elevations were observed with idelalisib treatment. A dose of $150 \mathrm{mg}$ BID was brought forward 
for subsequent studies [20]. Idelalisib has also shown promising single-agent activity in relapsed/refractory MCL $[21,80]$, yielding response rates similar to those previously reported for standard single-agent therapies in this setting $[81,82]$. Long term data reported by Spurgeon et al. showed that idelalisib given to patients with relapsed/refractory MCL resulted in an overall response rate of $40 \%$, with higher rates in patients dosed at $\geq 100 \mathrm{mg}$ BID [21]. Trial results of single-agent idelalisib in patients with indolent non-Hodgkin's lymphoma (including FL, SLL, LPL/WM, MZL) showed an overall response rate (ORR) of $48 \%$ across all cohorts [63]. Among 11 patients with SLL, the response rate was $64 \%$, whereas five of the 9 patients with LPL/WM responded, suggesting that idelalisib could be more effective in these subgroups [63].

Subsequently, a number of trials have examined idelalisib in combination regimens with a view to achieving clinically meaningful benefit. When idelalisib (I) was combined with rituximab $(\mathrm{R})$ and/or bendamustine $(\mathrm{B})$ in heavilypretreated relapsed/refractory CLL patients, Coutre and coworkers documented an impressive response rates of 78,82 , and 87 percents for IR, IB, and IRB regimens respectively [83]. These combinations appear to be more effective than responses reported for RB (rituximab plus bendamustine) in previous studies of patients with relapsed/refractory CLL $[84,85]$. In the updated efficacy analysis of the current study, responses appear to be very durable [22]. The 2-year PFS and OS were 62\% and $85 \%$ respectively [22]. Safety analysis indicated no overlap of key toxicities [22]. One study evaluated idelalisib plus ofatumumab as salvage therapy in relapsed/refractory CLL [86]. The study was small, evaluating only 20 patients, but interestingly, ORR was $94 \%$ in patients who had received 6 cycles or more, and appears to be superior to ofatumumab alone in this patient population [87]. The regimen was well tolerated and associated with marked and rapid reductions in lymphadenopathy within the first 2 cycles [86]. Given these favorable results, a phase III randomized, double-blind, placebo-controlled study has been initiated to assess the efficacy and safety of idelalisib in combination with bendamustine and rituximab versus placebo plus bendamustine and rituximab for previously treated CLL patients [88]. Likewise, another phase III randomized, controlled study is currently recruiting to examine idelalisib in combination with ofatumumab compared with ofatumumab alone in same patient population who had progressed after a purine analog and/or bendamustine [89].

In addition, a phase I trial employing the IR, IB, and IRB combination approaches was noteworthy for its associated response rates of $77 \%, 85 \%$, and $79 \%$ respectively in patients with iNHL [90]. Though responses were high, it appears that they were not better than the $90 \%$ response rate achieved by the landmark study by Rummel et al. with rituximab and bendamustine in patients with relapsed/ refractory iNHL [91]. Therefore, head-to-head comparison between idelalisib plus bendamustine and rituximab versus placebo plus bendamustine and rituximab in heavilypretreated patients with iNHL has been initiated in a phase III trial [92]. At the same time, another phase III randomized trial will be comparing idelalisib plus rituximab versus placebo plus rituximab in similar patient population [93]. The primary endpoint of these studies is progression-free survival (PFS) [93].

The clear benefit of idelalisib in combination with chemotherapy and/or immunotherapy in CLL has lent support for the development of these approaches in patients with MCL. Preliminary results of a phase I study of 22 patients showed that the combinations of idelalisib and everolimus (IE), bortezomib (IV), or bendamustine plus rituximab (IRB) were active and tolerable in previouslytreated patients with MCL [94]. Response rates were 25\% for IE, $50 \%$ for IV, and $100 \%$ for IRB. Given that BR has been shown to elicit responses of 75 to 92 percent in similar patient population, the activity of IRB appears to be similar to what can be achieved with RB alone [91,95]. Nonetheless, these findings are preliminary and further research is required before any conclusions can be drawn.

The optimal first-line therapy for elderly patients with CLL is not currently known as most treatment options have not been directly compared. This remains the subject of multiple ongoing studies [19,96-98]. Based partly on the impressive response rate of idelalisib plus rituximab in the relapsed/refractory CLL setting [83], O'Brien et al. are addressing whether this IR regimen $\left(\mathrm{R} 375 \mathrm{mg} / \mathrm{m}^{2}\right.$ weekly $\times 8$ and idelalisib $150 \mathrm{mg}$ bid continuously for 48 weeks) can be used in treatment-naïve, elderly patients with CLL/SLL [23]. Interim data regarding safety showed that the combination was tolerable, with diarrhea, pyrexia, chills, and fatigue being the most frequently reported adverse events. Of 48 patients evaluated for efficacy, the ORR was $96 \%$, and estimated 24-month PFS is $91 \%$, indicating that this approach is highly durable and paved the way for further study as upfront therapy in treatment-naïve elderly patients with CLL. Of note, six patients with del17p included in the study displayed $1 \mathrm{CR}$ and 5 PR [23].

Overall, idelalisib looks impressive as both a single agent and when given in combination with standard therapies across multiple subtypes of non-Hodgkin's lymphoma.

\section{Buparlisib (BKM 120, NVP-BKM120)}

Buparlisib, also known as BKM 120 and NVP-BKM120, is an orally bioavailable, small molecule compound with potent, pan-class I PI3K inhibitory property against p110$\alpha,-\beta,-\delta$, and $-\gamma$ enzymes at IC50 of $52 \mathrm{nM}, 166 \mathrm{nM}, 116$ $\mathrm{nM}$, and $262 \mathrm{nM}$ respectively [99]. As a derivative of pyridinamine, buparlisib shows great anti-proliferative activity 
in human gastric cancer cell lines, induces apoptotic cell death in multiple myeloma cells (ARP1, ARK, MM.1S, MM1.R and U266), and significantly reduces tumor volume and level of circulating human kappa light chain at $5 \mu \mathrm{M} / \mathrm{kg} /$ day in ARP1 SCID mouse model $[99,100]$. In vivo studies have also shown that buparlisib potently inhibits the growth of human xenografts models of metastatic brain melanoma, uterine endometriod carcinoma and carcinosarcoma, concomitant with suppression of PI3K phosphorylation [101,102]. Based on these promising preclinical data, buparlisib was advanced into clinical development.

The safety and preliminary clinical activity of buparlisib was first evaluated in a phase I study of 35 patients with advanced solid tumors by employing a dose-escalating design [103]. Overall, the compound was well tolerated. Dose limiting toxicities (DLTs) included grade 3/4 hyperglycemia, rash and mood alteration. The maximum tolerated dose (MTD) of $100 \mathrm{mg} /$ day is deemed to be suitable for future studies. Aberrant PI3K signaling is common in glioblastoma multiforme (GBM) and confers worse prognosis [104], however buparlisib has demonstrated an ability to cross the blood-brain barrier in preclinical models. The preliminary results from two early phase trials of buparlisib in patients with relapsed/refractory GBM have been recently reported. Shih and colleagues found that buparlisib at $60 \mathrm{mg} /$ day in combination with standard dose of bevacizumab was well tolerated [105]. Wen et al. showed that single-agent buparlisib at $100 \mathrm{mg} /$ day is generally safe in patients with recurrent GBM. Major grade 3/4 toxicities were similar to those previously reported for the compound [106]. Buparlisib has also been evaluated in a number of other patient populations for which positive results have been reported. A combination of buparlisib and letrozole demonstrated activity at clinically relevant doses of each agent in hormone receptor (HR)-positive metastatic breast cancer (MBC) patients who had received prior aromatase-inhibitor therapy in a phase I study [107]. This potential superiority yielded by adding buparlisib to standard therapy in $\mathrm{MBC}$ has led to the initiation of two phase III trials. BELLE-2 and BELLE-3 are evaluating buparlisib with fulvestrant in postmenopausal women with $\mathrm{HR}+/ \mathrm{HER} 2$ - advanced/ metastatic breast cancer after failure of aromatase inhibitor alone or aromatase inhibitor plus mTOR inhibitor treatment respectively [108]. A placebo-controlled phase II trial of buparlisib with paclitaxel in the first-line treatment of HER2-negative MBC (BELLE-4) is underway. A recent neoadjuvant phase II study of paclitaxel plus trastuzumab, with and without buparlisib (Neo-PHOEBE) in HER2overexpressing breast cancer patients is also accruing. Though buparlisib in combination with geftinib was found to be safe, high frequency of severe late toxicities, including rash and diarrhea was noted in patients with EGFR TKI- resistant NSCLC in a phase IB study, and alternative dosing schedules are thus warranted in subsequent studies [109].

\section{GDC-0941}

GDC-0941, a thienopyrimidine derivative, is another orally bioavailable, pan-class I PI3K inhibitor with equipotent activity $(\mathrm{IC} 50=3 \mathrm{nM})$ against $\mathrm{p} 110-\alpha$ and $-\delta$ enzymes, and exhibits inhibitory action against p110- $\beta$ and $-\gamma$ at low nanomolar concentrations in kinase assays [110]. GDC-0941, as a single agent or in combination with other therapies, has demonstrated potent antitumor activity against a panel of mouse xenograft models of human glioblastoma, breast cancer, small bowel gastrointestinal stromal tumor (GIST), follicular cell lymphoma, liposarcoma, and NSCLC [110-116].

GDC-0941 is the first-in-human PI3K inhibitor to enter clinical trials. GDC-0941 monotherapy is generally well tolerated at doses below $450 \mathrm{mg}$ once or twice a day in patients with advanced solid tumors [117]. The most common adverse events were nausea, diarrhea, vomiting, fatigue, decreased appetite, dysgeusia, and rash. In the updated efficacy analyses, clinically meaningful responses have been achieved with single-agent GDC-0941 in patients with endocervical carcinoma, breast cancer, soft tissue sarcoma, ovarian carcinoma, small bowel GIST and V600E mutant melanoma [117-120]. Given the single-agent activity of GDC-0941 in earlier studies, testing the drug in combination was seen as a logical step to maximize benefit. Concurrent administration of GDC-0941 and GDC-0973, a potent, selective, MEK1/2 inhibitor was well tolerated in patients with advanced solid tumors. No new safety signal has emerged, and clinical responses have been observed in patients with melanoma, pancreatic cancer, NSCLC, prostate cancer, and endometrioid cancer [121,122]. The synergistic efficacy of GDC-0941 and anti-VEGF directed therapy is being evaluated in a phase IB trial of GDC-0941 with paclitaxel and carboplatin, with and without bevacizumab in patients with advanced NSCLC. Partial responses were seen in $44 \%$ patients, including 1 pathologic CR upon resection of the primary lung lesion [123]. Phase II studies of GDC-0941 are underway.

\section{PX-866}

PX-866 is a semisynthetic analogue of wortmannin with potent, irreversible, pan-class I PI3K inhibitory property against purified $\mathrm{p} 110-\alpha,-\delta$, and $-\gamma$ enzymes at nanomolar concentrations in biochemical assays. Unlike wortmannin, PX-866 is a poor inhibitor of p110- $\beta[124,125]$. In preclinical studies, the compound alone or in combination with chemotherapy, radiation or other targeted cancer drugs, exhibited in vivo antitumor activity against numerous mouse xenograft models of human cancers [124,125]. 
Safety results from 52 patients indicated that PX-866 was well tolerated, with diarrhea being the DLT, and no drug-related serious hematologic adverse events reported [126]. The MTD of $8 \mathrm{mg}$ was recommended for subsequent studies. Updated antitumor results of this trial demonstrated that PX-866 in combination with docetaxel was efficacious in patients with NSCLC and ovarian cancer (2 PR) [127]. Preliminary results from two randomized phase II clinical trials of PX-866 have been recently reported. In the first study, PX-866 displayed a very low ORR of 3\% in 33 patients with recurrent GBM [128]. A second study explored the efficacy of PX-866 as second- or third-line treatment of docetaxel-naive patients with recurrent or metastatic castration-resistant prostate cancer (CRPC). Of 16 patients evaluated for efficacy, no objective response was observed [129]. Other phase II trials are currently ongoing in a variety of tumor types.

\section{GDC-0032}

GDC-0032 is a selective inhibitor of class I PI3K- $\alpha,-\delta$, and $-\gamma$ isoforms in subnanomolar concentrations. It is an orally bioavailable small molecule with $\beta$ isoform sparing inhibitory property. Treatment with GDC-0032 enhances activity of fulvestrant, resulting in tumor regressions and growth delay in preclinical animal models of human breast cancer $[130,131]$. A first-in-human phase IA clinical trial has been undertaken to assess the safety, pharmacokinetics and pharmacodynamics of GDC-0032 in 34 patients with locally advanced or metastatic solid tumors [132]. Results of this study indicated that the drug was well tolerated with hyperglycemia and fatigue being the dose-limiting toxicities. Five partial responses were observed in breast and NSCLC. Additional phase I trials are accruing patients.

\section{BAY 80-6946}

BAY 80-6946 is a carboxamide derivative with potent antineoplastic activity characterized by reversible inhibition of p110- $\alpha$ and $-\beta$ with IC50 of $0.469 \mathrm{nM}$ and $3.72 \mathrm{nM}$ respectively in biochemical assays, and growth-inhibitory effects in B-cell lymphoma and biliary tract carcinoma cell lines $[133,134]$.

BAY 80-6946 was administered intravenously as 1-hour infusion once weekly for 3 weeks every month in a phase I dose-escalation trial of 17 patients with advanced solid tumors, including sarcoma, pancreatic, and esophageal cancers. It was well-tolerated [135,136]. Acute left ventricular dysfunction, liver dysfunction, renal insufficiency, hyperglycemia, and rash were the DLTs. The MTD was $0.8 \mathrm{mg} / \mathrm{kg}$ [136]. In a MTD expansion cohort study, 5 heavily pretreated patients demonstrated a PR to therapy [137]. More so, BAY 80-6946 has also demonstrated efficacy and safety among patients with both indolent and aggressive NHLs. These data have fuelled the enthusiasm for further clinical development of this compound either as a single agent or in combination regimens in patients with NHL [135].

\section{IPI-145}

IPI-145 (formerly INK1197) is an oral, selective inhibitor of $\mathrm{p} 110-\delta$ and $-\gamma$ isoforms at picomolar concentrations in enzyme assays. IPI-145 was initially developed as anti-inflammatory compound, displaying potent suppression of both B- and T-cell proliferation, and demonstrating dose-dependent anti-inflammatory effect in rat collagen induced arthritis (CIA) and adjuvant induced polyarthritis models.

The pharmacokinetics, safety and efficacy of IPI-145 have been studied in early phase clinical trials that included healthy subjects as well as patients with advanced hematologic malignancies $[138,139]$. The compound was well tolerated at doses up to $25 \mathrm{mg}$ BID, exhibited excellent target inhibition (CD63 expression), and showed initial clinical activity in patients with iNHL, MCL, and CLL [139]. The main DLT was grade 4 neutropenia. Additional safety and efficacy data are expected from the ongoing trials.

\section{BEZ-235}

BEZ-235 (formerly NVP-BEZ235), a novel imidazoquinoline derivative, is a dual ATP-competitive PI3K and mTOR inhibitor with potent antagonist activity against $\mathrm{p} 110-\alpha,-\beta,-\gamma,-\delta$ isoforms and mTOR (p70S6K) in nanomolar concentrations [140]. In vitro, BEZ-235 possesses strong anti-proliferative activity characterized by robust growth arrest in the G1 phase of many PTEN-negative malignancies, both in cell lines and in ex vivo cells $[140,141]$. Also BEZ-235 potently inhibits VEGF-induced cell proliferation and survival in vitro and VEGF-induced angiogenesis in vivo [142], and effectively reverses lapatinib-resistance in HER2 breast cancer cells [143]. Additionally, BEZ-235 as a single therapy or in combination with other agents exhibited antitumor activity against numerous mouse xenograft models of human cancers including gliomas, pancreatic cancer, sarcoma, ovarian cancer, renal cell carcinoma, breast cancer, and hepatocellular carcinoma [144-148].

The phase I study conducted by Arkenau et al. to determine the safety of single-agent BEZ-235 included 12 patients with advanced solid tumor with dose-level randomization into 4 cohorts [149]. Preliminary results of this study showed that BEZ-235 at $600 \mathrm{mg}$ BID was well tolerated with mucositis being the most frequent DLT [149]. The combination of BEZ-235 and trastuzumab has been evaluated in a phase IB/II clinical trial in trastuzumab-resistant HER2+ MBC [150]. The doublet therapy demonstrated an acceptable safety profile and early sign of clinical activity. Preliminary safety data from another phase IB/II combination study of BEZ-235 with everolimus 
indicated that the regimen is safe, with no DLTs observed so far and the trial remains open to further accrual [151,152].

\section{BYL-719}

BYL-719, a dicarboxamide analogue, is the first, orally bioavailable, potent selective inhibitor of PI3K- $\alpha$ with IC50 of $5 \mathrm{nM}$ in kinase assays. Preclinical data suggested that the compound prevents phosphorylation of AKT and inhibits growth and PI3K signaling in breast cancer cell lines harboring PIK3CA mutations [153]. Dose-dependent antitumor activity was shown in a PIK3CA-mutant mouse xenograft models [153]. Treatment of MCF7 breast cancer cells and mouse xenograft models with BYL-719 and ganitumab, a fully human antibody against IGF1-R, resulted in synergistic, concentration-dependent growth arrest and tumor regression [154].

Based on these results, a phase I trial enrolled patients with PIK3CA-mutant advanced solid tumors, including estrogen receptor-positive $(\mathrm{ER}+) \mathrm{MBC}$ [155]. Interim results showed that hyperglycemia, nausea, vomiting, and diarrhea were the DLTs, and $400 \mathrm{mg}$ orally daily was declared as the MTD. Partial responses were seen in patients with breast, cervical, endometrial, ovarian, and head and neck cancer [155].

\section{BGT-226}

BGT-226 (formerly NVP-BGT226) is another novel, dual pan-class I PI3K/mTOR antagonist with inhibitory property against p110- $\alpha,-\beta$, and $-\gamma$ isoforms with IC50 of $4 \mathrm{nM}, 63$ $\mathrm{nM}$, and $38 \mathrm{nM}$ in enzyme assays [156]. BGT-226 led to cell cycle arrest in the G0/G1 phase and inhibited growth in a variety of human cancer cell lines, including those that harbor the PIK3CA mutation [156-159]. Robust cancer cell death via apoptotic and non-apoptotic pathways, as well as induction of autophagy through microtubule-associated protein light chain 3B-II aggregation and p62 degradation are also associated with BGT-226 treatment [157]. In vivo studies have shown that oral doses of BGT-226 at 2.5 and $5 \mathrm{mg} / \mathrm{kg}$ for 3 weeks inhibit cytoplasmic expression of p70 S6 kinase and enhance autophagosome formation, translating into potent inhibition of tumor growth in human xenograft models [157].

A dose finding phase I study of BGT-226 indicated that the MTD was $125 \mathrm{mg}$ per day or three times weekly, with $100 \mathrm{mg} /$ day recommended as clinical dose for subsequent studies [156]. Most common BGT226-related adverse events included nausea, diarrhea, and vomiting. The best response of stable was demonstrated in patients with advanced solid tumors. The safety and efficacy data of other trials are awaited with great interest.

\section{PF-04691502}

Like BGT-226, PF-04691502 is also a novel, ATPcompetitive, dual pan-class I PI3K/mTOR inhibitor with activity against numerous human cancer cell lines at nanomolar concentrations [160,161]. PF-04691502 reduces levels of phosphorylated AKT (pAKT) T308 and S473, and its activity is not affected by presence of PIK3CA or PTEN mutations [160]. The compound also exhibits activity in animal models of KRAS-mutant non-small cell lung carcinoma xenografts, and thus potentially represents an effective therapeutic intervention for NSCLC patients with gefitinib- or erlotinib-resistant disease [160].

Updated data from the first-in-human phase I study aimed to establish the MTD, clinical activity, pharmacokinetics, and pharmacodynamics of PF-04691502 in 30 patients with advanced solid tumors. PF-04691502 appears to be safe and tolerable at a variety of dose levels [162]. Eight milligrams once daily is established as the MTD, and the most common adverse events noted were fatigue, nausea, vomiting, decreased appetite and rash. A phase II trial of PF-04691502 in combination with another dual PI3K/mTOR inhibitor, PF-05212384, in advanced endometrial cancer is currently recruiting.

\section{GDC-0980}

GDC-0980 (formerly RG7422) is a novel, oral, dual $\mathrm{PI} 3 \mathrm{~K} / \mathrm{mTOR}$ inhibitor synthesized using the GDC-0941 backbone [163]. In biochemical assays, GDC-0980 demonstrates its ability to inhibit the enzymatic activities of p110- $\alpha,-\beta,-\delta,-\gamma$ and mTOR at IC50 of $5 \mathrm{nM}, 27 \mathrm{nM}$, $7 \mathrm{nM}, 14 \mathrm{nM}$, and $17 \mathrm{nM}$ respectively [163]. In in-vitro experiments, potent anti-proliferative and pro-apoptotic effects of GDC-0980 were observed in prostate, breast and NSCLC cell lines, whereas modest activities were noted in pancreatic and melanoma cell lines [164]. In general, GDC-0980 demonstrated significant tumor growth inhibition in a wide range of xenografts derived from prostate, breast, ovarian, and lung cancer cell lines at doses of $\leq 7.5 \mathrm{mg} / \mathrm{kg}$ [163]. The compound was well tolerated and clinically efficacious in animal models at $55 \mathrm{mg}$ given once daily without significant toxicities [165]. Recent preclinical studies have also shown that GDC-0980 combined with ABT888 (PARP inhibitor) and carboplatin seems to be approximately 2 times more potent than GDC-0980 alone at growth suppression in BRCAcompetent triple negative breast cancer cell lines [166].

The safety, pharmacokinetics, pharmacodynamics and efficacy of GDC-0980 were first assessed in 33 patients with advanced solid malignancies in a dose-escalation phase I study [167]. Patients were enrolled in seven cohorts at dosage levels ranging from 2-70 mg once daily for 21 consecutive days of a 28 -day cycle. Serious treatmentrelated adverse events included grade 3 maculopapular rash, symptomatic hyperglycemia, mucositis, and pneumonitis which resolved with drug cessation and medical management. Pharmacodynamic assessments revealed $>90 \%$ 
inhibition of pAKT levels at dosage levels of $16 \mathrm{mg}$ or above. GDC-0980 also showed promising antitumor activity, with RECIST and/or FDG-PET partial response rates up to $64 \%$ [167]. The recommended phase II dose for single-agent GDC-0980 is $40 \mathrm{mg}$ daily. Several phase IB/II trials of GDC-0980 in combination with experimental or approved agents have been initiated. For example, the safety and efficacy of combination of GDC-0980 and abiraterone versus abiraterone alone are being evaluated in castration-resistant prostate cancer patients [168].

\section{GSK-2126458}

GSK-2126458 is a potent, selective, second generation inhibitor of $\mathrm{p} 110-\alpha,-\beta,-\gamma,-\delta$, mTORC1, and mTORC2. It blocks PI3K/mTOR signaling at subnanomolar drug concentrations. Relative potency of GSK-2126458 in kinase assays is 100-1000 times greater than that of GDC-0980 [169]. Additionally, inhibition of the PI3K/ mTOR pathway by this agent has shown activity in breast cancer cells in preclinical studies, particularly the PIK3CAmutant subsets [169]. Dose-dependent antitumor activity was shown in BT474 mouse xenograft model, with significant response at a dose as low as $300 \mu \mathrm{g} / \mathrm{kg}$.

While clinical experience with this compound is quite limited to date, the preliminary results of an early phase trial in seventy-eight patients with advanced solid tumors indicated that GSK-2126458 was safe, demonstrated on-target inhibition of PI3K, and diarrhea was the DLT [170]. Two patients with renal cell carcinoma and bladder cancer experienced partial response. When dosed once daily, a MTD of $2.5 \mathrm{mg}$ was observed. Another phase I trial of GSK-2126458 in combination with oral MEK inhibitor GSK1120212 is planned.

\section{PF-05212384 (PKI-587)}

Another novel, highly potent, dual PI3K/mTOR inhibitor is PF-05212384 (also known as PKI-587), which selectively binds to PI3K- $\alpha$, PI3K- $\gamma$ and mTOR and inhibits phosphorylation of both mTOR and AKT, and PI3K signaling. PF-05212384 leads to cell cycle inhibition and subsequent mitotic arrest, inhibition of proliferation, and apoptosis [171]. In vivo pharmacokinetics and pharmacodynamics suggested that intravenous PF-05212384 treatment is associated with low plasma clearance, high volume of distribution, long half-life, and robust antitumor efficacy in xenograft mouse models.

PF-05213384 is the first intravenously formulated $\mathrm{PI} 3 \mathrm{~K} / \mathrm{mTOR}$ inhibitor to be tested in a clinical trial. In a phase I trial, Millham and colleagues used a modified continual reassessment method (CRM) for estimation of MTD. PF-05212384 was administered weekly at doses ranging from $10 \mathrm{mg}$ to $319 \mathrm{mg}$ [172]. A total of $47 \mathrm{pa}$ tients with advanced or refractory solid tumors were enrolled, including 8 patients with colorectal cancer.
DLTs included mucositis, rash, transaminase elevation, and hyperglycemia. The MTD was $154 \mathrm{mg}$ weekly. No objective tumor response was observed, but 12 patients achieved stable disease during the study [172]. Recruitment to phase II trials is ongoing.

\section{XL765}

A methylbenzamide derivative, XL765 (also known as SAR245409) is an orally active, multikinase (PI3K/mTOR) inhibitor with highly potent activity particularly for the p110- $\gamma$ isoform in biochemical assays [173]. The compound was shown to inhibit proliferation and induce apoptosis in various tumor cell lines $[173,174]$. It demonstrated activity as monotherapy and in combination with temozolamide (TMZ) in GBM xenografts [175].

Data from a phase I dose escalation study of 34 patients with advanced or metastatic solid tumors indicate that XL765 is safe, and the most frequently observed adverse events included elevated liver enzymes, nausea and diarrhea [176]. XL765 combined with erlotinib demonstrated no additive toxicity, and generally well tolerated at daily doses up to $50 \mathrm{mg}$ and $100 \mathrm{mg}$ respectively [177]. Another trial showed that XL765 in combination with fixed standard dose of TMZ in 18 previously-treated patients with relapsed/refractory WHO grade III and IV astrocytic tumors was safe and generally well tolerated at doses up to $40 \mathrm{mg}$ once daily [178]. Notably, the most serious treatmentrelated adverse events were rash, thrombocytopenia, and brain edema. Phase IB/II clinical trials of XL765 as a single agent and in combination with other targeted agents or cytotoxic chemotherapy are planned.

\section{XL147}

XL147 (SAR245408) is an investigational methylbenzenesulfonamide derivative and a novel PI3K inhibitor. Preclinical studies demonstrated that XL147 exhibits pan-class I PI3K inhibitory property through reversible, competitive inhibition with ATP for $\mathrm{p} 110-\alpha,-\delta,-\gamma$, and $-\beta$ enzymes at IC50 of $39 \mathrm{nM}, 36 \mathrm{nM}, 23 \mathrm{nM}$, and $383 \mathrm{nM}$ respectively [179]. Additional preclinical data indicated that the main action of XL147 is inhibition of cell proliferation and growth, accompanied by abrogation of AKT and S6 phosphorylation, and reduction in cyclin D1 and pRB and an upregulation in levels of the CDK inhibitor p27 [179]. In a panel of HER2+ breast cancer cells, treatment with trastuzumab or lapatinib sensitizes tumor cells to the growth-inhibitory effect of XL147. Based on this preclinical rationale, XL147 has been evaluated in phase I and phase II clinical trials.

In an initial phase I trial with standard $3+3$ doseescalation design, 68 patients with advanced solid tumor were treated with XL147 administered on days 1-21 (21/7) every 4 weeks per treatment cycle or as a continuous daily dose (CDD) in 28-day cycle. The MTD, identified for both 
schedules, was $600 \mathrm{mg}$. Grade 3 rash was the DLT for the 21/7 schedule, whereas no DLTs were noted for the CDD dosing [180]. Pharmacokinetic data from another phase I study showed that treatment with XL147 plus erlotinib is associated with no major interaction, well-tolerated, and demonstrated robust concomitant EGFR and PI3K inhibition [181]. A clinical regimen of XL147, paclitaxel and carboplatin may synergistically augment suppression of PI3K signaling and enhance clinical effect. Interim data showed partial response rates of $\geq 42 \%$ by RECIST criteria in four patients with advanced solid tumor [182]. A recently presented study of patients with recurrent GBM has also provided further insight into the cellular pharmacodynamics and in vivo pharmacokinetics of XL147, where higher tumor to plasma drug concentration ratios were noted in resected tissue specimen, along with decreased Ki67 index consistent with inhibition of proliferation [183]. Additional clinical evaluation of this PI3K inhibitor is ongoing in phase I/ II studies.

\section{Conclusion and future directions}

Phosphatidylinositol 3-kinases (PI3Ks) are attractive molecular targets for novel anti-cancer molecules. In the last few years, several classes of potent and selective small molecule PI3K inhibitors have been developed, and at least fifteen compounds have progressed into clinical trials as new anticancer drugs. Among these, idelalisib looks impressive as both a single agent and when given in combination with standard therapies across multiple subtypes of non-Hodgkin's lymphoma. Phase III clinical trials are actively recruiting. Future trials of combining novel small molecule inhibitors against different signaling pathways as well as combination of these inhibitors with biological and biochemical agents may further enhance their clinical efficacy $[41,184-189]$.

\begin{abstract}
Abbreviations
AMPK: $5^{\prime}$ adenosine monophosphate-activated protein kinase; BAD: BCl-2-associated death promoter; FAK: Focal adhesion kinase; FOXO: Forkhead box protein O; GPCR: G protein coupled receptors; GSK3: Glycogen synthase kinase 3; JNK: c-Jun N-terminal kinases; LKB1: Liver kinase B1; MDM2: Mouse double minute 2 homolog; mTOR C1: Mammalian target of rapamycin complex 1; NF-kB: Nuclear factor kappa-light-chain-enhancer of activated B cells; PDK1: Pyruvate dehydrogenase lipoamide kinase isozyme 1; PI3K: Phosphatidylinositide 3-kinases; PIP3: Phosphatidylinosito $(3,4,5)$-triphosphate; PTEN: Phosphatase and tensin homolog; RHEB: Ras homolog enriched in brain; RTK: Receptor tyrosine kinase; SHIP: SH2-containing inositol phosphatase; TCS1/2: Two-component signal transduction protein 1/2
\end{abstract}

\section{Competing of interests}

The authors declare that they have no competing interests.

\section{Authors' contributions}

$\mathrm{AA}$ and PA contributed equally. All authors have contributed to data preparation, drafting and revising the manuscripts. All authors have read and approved the final manuscript.

\section{Acknowledgments}

This study was partly supported by New York Medical College Blood Diseases Fund.
Received: 17 October 2013 Accepted: 12 November 2013

Published: 22 November 2013

\section{References}

1. Cantley LC: The phosphoinositide 3-kinase pathway. Science 2002, 296(5573):1655-1657.

2. Burris HA 3rd: Overcoming acquired resistance to anticancer therapy: focus on the PI3K/AKT/mTOR pathway. Cancer Chemother Pharmacol 2013, 71(4):829-842

3. Osaki M, Oshimura M, Ito H: PI3K-Akt pathway: its functions and alterations in human cancer. Apoptosis 2004, 9(6):667-676.

4. Akinleye A, Chen Y, Mukhi N, Song Y, Liu D: Ibrutinib and novel BTK inhibitors in clinical development. J Hematol Oncol 2013, 6(1):59.

5. Hu C, Huang L, Gest C, Xi X, Janin A, Soria C, Li H, Lu H: Opposite regulation by PI3K/Akt and MAPK/ERK pathways of tissue factor expression, cell-associated procoagulant activity and invasiveness in MDA-MB-231 cells. J Hematol Oncol 2012, 5(1):16.

6. Arteaga $\mathrm{CL}$ : Clinical development of phosphatidylinositol-3 kinase pathway inhibitors. Curr Top Microbiol Immunol 2010, 347:189-208.

7. Sawyers CL: Will kinase inhibitors have a dark side? N Engl J Med 2006 355(3):313-315.

8. Shaw $\mathrm{R}$, et al: Ras, $\mathrm{PI}(3) \mathrm{K}$ and $\mathrm{mTOR}$ signalling controls tumour cell growth. Nature 2006, 441(7092):424-430.

9. Zitzmann K, De Toni EN, Brand S, Goke B, Meinecke J, Spottl G, Meyer HH, Auernhammer CJ: The novel mTOR inhibitor RAD001 (everolimus) induces antiproliferative effects in human pancreatic neuroendocrine tumor cells. Neuroendocrinology 2007, 85(1):54-60.

10. Patel S: Exploring Novel Therapeutic Targets in GIST: Focus on the PI3K/ Akt/mTOR Pathway. Curr Oncol Rep 2013, 15(4):386-395.

11. Slomovitz B, et al: The PI3K/AKT/mTOR pathway as a therapeutic target in endometrial cancer. Clin Cancer Res 2012, 18(21):5856-5864.

12. Samuels Y, Wang Z, Bardelli A, Silliman N, Ptak J, Szabo S, Yan H, Gazdar A, Powell SM, Riggins GJ, et al: High frequency of mutations of the PIK3CA gene in human cancers. Science 2004, 304(5670):554

13. Liu P, et al: Targeting the phosphoinositide 3-kinase pathway in cancer. Nat Rev Drug Discov 2009, 8(8):627-644.

14. Miller $\mathrm{T}$, et al: Phosphatidylinositol 3-kinase and antiestrogen resistance in breast cancer. J Clin Oncol 2011, 29(33):4452-4461.

15. Thomas RK, Baker AC, Debiasi RM, Winckler W, Laframboise T, Lin WM, Wang M, Feng W, Zander T, MacConaill L, et al: High-throughput oncogene mutation profiling in human cancer. Nat Genet 2007, 39(3):347-351.

16. Engelman JA: Targeting PI3K signalling in cancer: opportunities, challenges and limitations. Nat Rev Cancer 2009, 9(8):550-562.

17. Markman B, Atzori F, Perez-Garcia J, Tabernero J, Baselga J: Status of PI3K inhibition and biomarker development in cancer therapeutics. Ann Oncol 2010, 21(4):683-691.

18. Xu C, Zhou Q, Wu Y-l: Can EGFR-TKIs be used in first line treatment for advanced non-small cell lung cancer based on selection according to clinical factors ? - A literature-based meta-analysis. J Hematol Oncol 2012, 5(1):62.

19. Wu M, Akinleye A, Zhu X: Novel agents for chronic lymphocytic leukemia. J Hematol Oncol 2013, 6:36

20. Brown JR, Furman RR, Flinn I, Coutre SE, Wagner-Johnston ND, Kahl BS, Spurgeon SEF, Benson DM, Peterman S, Johnson DM, et al: Final results of a phase I study of idelalisib (GSE1101) a selective inhibitor of PIKK\{delta\}, in patients with relapsed or refractory CLL. ASCO Meeting Abstracts 2013, 31(15_supp):7003.

21. Spurgeon $\mathrm{E}$, et al: Final results of a phase I study of idelalisib, a selective inhibitor of phosphatidylinositol 3-kinase P110\{delta\} (PI3K\{delta\}), in patients with relapsed or refractory mantle cell lymphoma (MCL). ASCO Meeting Abstracts 2013, 31(15_suppl):8519.

22. Barrientos J, et al: Update on a phase I study of the selective PI3Kס inhibitor idelalisib (GS-1101) in combination with rituximab and/or bendamustine in patients with relapsed or refractory CLL. J Clin Oncol 2013, 31(suppl). abstr 7017

23. O'Brien SM, Lamanna N, Kipps TJ, Flinn I, Zelenetz AD, Burger JA, Holes L, Johnson DM, Gu J, Dansey RD, et al: A phase II study of the selective phosphatidylinositol 3-kinase delta (PI3K\{delta\}) inhibitor idelalisib (GS-1101) in combination with rituximab (R) in treatment-naive patients (pts) > $=65$ years with chronic lymphocytic leukemia (CLL) or small lymphocytic lymphoma (SLL). ASCO Meeting Abstracts 2013, 31(15_suppl):7005. 
24. Courtney $\mathrm{K}$, et al: The PI3K pathway as drug target in human cancer. J Clin Oncol 2010, 28(6):1075-1083.

25. Vanhaesebroeck B, Leevers SJ, Panayotou G, Waterfield MD: Phosphoinositide 3-kinases: a conserved family of signal transducers. Trends Biochem Sci 1997, 22(7):267-272.

26. Engelman J, et al: The evolution of phosphatidylinositol 3-kinases as regulators of growth and metabolism. Nat Rev Genet 2006, 7(8):606-619.

27. Katso R, Okkenhaug K, Ahmadi K, White S, Timms J, Waterfield MD: Cellular function of phosphoinositide 3-kinases: implications for development, homeostasis, and cancer. Annu Rev Cell Dev Biol 2001, 17:615-675.

28. Yu J, Zhang Y, Mcllroy J, Rordorf-Nikolic T, Orr GA, Backer JM: Regulation of the p85/p110 phosphatidylinositol 3'-kinase: stabilization and inhibition of the $\mathrm{p} 110 \mathrm{alpha}$ catalytic subunit by the $\mathrm{p} 85$ regulatory subunit. Mol Cell Biol 1998, 18(3):1379-1387.

29. Backer JM: The regulation and function of Class III PI3Ks: novel roles for Vps34. Biochem J 2008, 410(1):1-17

30. Stoyanov B, Volinia S, Hanck T, Rubio I, Loubtchenkov M, Malek D, Stoyanova S, Vanhaesebroeck B, Dhand R, Nurnberg B, et al: Cloning and characterization of a $\mathrm{G}$ protein-activated human phosphoinositide-3 kinase. Science 1995, 269(5224):690-693

31. Arcaro A, Zvelebil MJ, Wallasch C, Ullrich A, Waterfield MD, Domin J: Class II phosphoinositide 3-kinases are downstream targets of activated polypeptide growth factor receptors. Mol Cell Biol 2000, 20(11):3817-3830.

32. Gaidarov I, Smith ME, Domin J, Keen JH: The class II phosphoinositide 3-kinase C2alpha is activated by clathrin and regulates clathrin-mediated membrane trafficking. Mol Cell 2001, 7(2):443-449.

33. Gaidarov I, et al: Individual phosphoinositide 3-kinase C2alpha domain activities independently regulate clathrin function. J Biol Chem 2005, 280(49):40766-40772.

34. Volinia S, Dhand R, Vanhaesebroeck B, MacDougall LK, Stein R, Zvelebil MJ, Domin J, Panaretou C, Waterfield MD: A human phosphatidylinositol 3-kinase complex related to the yeast Vps34p-Vps15p protein sorting system. EMBO J 1995, 14(14):3339-3348.

35. Stein MP, Feng Y, Cooper KL, Welford AM, Wandinger-Ness A: Human VPS34 and p150 are Rab7 interacting partners. Traffic 2003, 4(11):754-771.

36. Carpenter CL, Auger KR, Chanudhuri M, Yoakim M, Schaffhausen B, Shoelson S, Cantley LC: Phosphoinositide 3-kinase is activated by phosphopeptides that bind to the $\mathrm{SH} 2$ domains of the $85-\mathrm{kDa}$ subunit. J Biol Chem 1993, 268(13):9478-9483.

37. Arcaro A, Volinia S, Zvelebil MJ, Stein R, Watton SJ, Layton MJ, Gout I, Ahmadi K, Downward J, Waterfield MD: Human phosphoinositide 3-kinase C2beta, the role of calcium and the C2 domain in enzyme activity. J Biol Chem 1998, 273(49):33082-33090.

38. Domin J, Pages F, Volinia S, Rittenhouse SE, Zvelebil MJ, Stein RC, Waterfield $\mathrm{MD}$ : Cloning of a human phosphoinositide 3-kinase with a C2 domain that displays reduced sensitivity to the inhibitor wortmannin. Biochem $J$ 1997, 326(Pt 1):139-147.

39. Turner SJ, Domin J, Waterfield MD, Ward SG, Westwick J: The CC chemokine monocyte chemotactic peptide-1 activates both the class I p85/p110 phosphatidylinositol 3-kinase and the class II PI3K-C2alpha. J Biol Chem 1998, 273(40):25987-25995.

40. Akinleye A, Furqan M, Mukhi N, Ravella P, Liu D: MEK and the inhibitors: from bench to bedside. J Hematol Oncol 2013, 6:27.

41. Furqan M, Mukhi N, Lee B, Liu D: Dysregulation of JAK-STAT pathway in hematological malignancies and JAK inhibitors for clinical application. Biomarker Research 2013, 1(1):5.

42. Lawlor $\mathrm{M}$, et al: PKB/Akt: a key mediator of cell proliferation, survival and insulin responses? J Cell Sci 2001, 114(Pt 16):2903-2910.

43. Bea V: The PI3K-PDK1 connection: more than just a road to PKB. Biochem J 2000, 346(Pt 3):561-576.

44. Vivanco I, et al: The phosphatidylinositol 3-Kinase AKT pathway in human cancer. Nat Rev Cancer 2002, 2(7):489-501.

45. Duronio V: The life of a cell: apoptosis regulation by the PI3K/PKB pathway. Biochem J 2008, 415(3):333-344.

46. Manning B, et al: AKT/PKB signaling: navigating downstream. Cell 2007 , 129(7):1261-1274

47. Brunet $A$, et al: Transcription-dependent and -independent control of neuronal survival by the PI3K-Akt signaling pathway. Curr Opin Neurobiol 2001, 11(3):297-305

48. Czech $M$, et al: Signaling mechanisms that regulate glucose transport. J Biol Chem 1999, 274(4):1865-1868.
49. Kawakami Y, Kitaura J, Hata D, Yao L, Kawakami T: Functions of Bruton's tyrosine kinase in mast and B cells. J Leukoc Biol 1999, 65(3):286-290.

50. Tuveson DA, Carter RH, Soltoff SP, Fearon DT: CD19 of B cells as a surrogate kinase insert region to bind phosphatidylinositol 3-kinase. Science 1993, 260(5110):986-989.

51. Jones RG, Parsons M, Bonnard M, Chan VS, Yeh WC, Woodgett JR, Ohashi PS: Protein kinase $B$ regulates $T$ lymphocyte survival, nuclear factor kappaB activation, and Bcl-X(L) levels in vivo. J Exp Med 2000, 191(10):1721-1734

52. Radisavljevic $Z$, et al: Vascular endothelial growth factor up-regulates ICAM-1 expression via the phosphatidylinositol $3 \mathrm{OH}$-kinase/AKT/Nitric oxide pathway and modulates migration of brain microvascular endothelial cells. J Biol Chem 2000, 275(27):20770-20774.

53. Suzuma K, Naruse K, Suzuma I, Takahara N, Ueki K, Aiello LP, King GL: Vascular endothelial growth factor induces expression of connective tissue growth factor via KDR, Flt1, and phosphatidylinositol 3-kinase-akt-dependent pathways in retinal vascular cells. J Biol Chem 2000, 275(52):40725-40731.

54. Shioi T, Kang PM, Douglas PS, Hampe J, Yballe CM, Lawitts J, Cantley LC, Izumo S: The conserved phosphoinositide 3-kinase pathway determines heart size in mice. EMBO J 2000, 19(11):2537-2548.

55. Clement S, Krause U, Desmedt F, Tanti JF, Behrends J, Pesesse X, Sasaki T, Penninger J, Doherty M, Malaisse W, et al: The lipid phosphatase SHIP2 controls insulin sensitivity. Nature 2001, 409(6816):92-97.

56. Gewinner C, Wang ZC, Richardson A, Teruya-Feldstein J, Etemadmoghadam D, Bowtell D, Barretina J, Lin WM, Rameh L, Salmena L, et al: Evidence that inositol polyphosphate 4-phosphatase type II is a tumor suppressor that inhibits PI3K signaling. Cancer Cell 2009, 16(2):115-125.

57. Blondeau F, Laporte J, Bodin S, Superti-Furga G, Payrastre B, Mandel JL: Myotubularin, a phosphatase deficient in myotubular myopathy, acts on phosphatidylinositol 3-kinase and phosphatidylinositol 3-phosphate pathway. Hum Mol Genet 2000, 9(15):2223-2229.

58. Bitting $\mathrm{R}$, et al: Targeting the PI3K/Akt/mTOR pathway in castration-resistant prostate cancer. Endocr Relat Cancer 2013, 20(3):R83-R99.

59. Pourmand G, Ziaee AA, Abedi AR, Mehrsai A, Alavi HA, Ahmadi A, Saadati HR: Role of PTEN gene in progression of prostate cancer. Urol J 2007, 4(2):95-100.

60. Taylor BS, Schultz N, Hieronymus H, Gopalan A, Xiao Y, Carver BS, Arora VK, Kaushik $P$, Cerami E, Reva B, et al: Integrative genomic profiling of human prostate cancer. Cancer Cell 2010, 18(1):11-22.

61. Benistant $C$, et al: A specific function for phosphatidylinositol 3-kinase alpha (p85alpha-p110alpha) in cell survival and for phosphatidylinositol 3-kinase beta (p85alpha-p110beta) in de novo DNA synthesis of human colon carcinoma cells. Oncogene 2000, 19(44):5083-5090.

62. Parsons DW, Jones S, Zhang X, Lin JC, Leary RJ, Angenendt P, Mankoo P, Carter H, Siu IM, Gallia GL, et al: An integrated genomic analysis of human glioblastoma multiforme. Science 2008, 321(5897):1807-1812

63. Benson $D$, et al: Final results of a phase I study of idelalisib, a selective inhibitor of $\mathrm{PI} 3 \mathrm{~K}\{$ delta\}, in patients with relapsed or refractory indolent non-Hodgkin lymphoma (iNHL). ASCO Meeting Abstracts 2013, 31(15_suppl):8526

64. Vadas O, Burke JE, Zhang X, Berndt A, Williams RL: Structural basis for activation and inhibition of class I phosphoinositide 3-kinases. Sci Signal 2011, 4(195):re2.

65. Martini M, et al: Targeting PI3K in Cancer: Any Good News? Front Oncol 2013, 3:108.

66. Arcaro A, et al: Wortmannin is a potent phosphatidylinositol 3-kinase inhibitor: the role of phosphatidylinositol 3,4,5-trisphosphate in neutrophil responses. Biochem J 1993, 296(Pt 2):297-301.

67. Liu Y, et al: Wortmannin, a widely used phosphoinositide 3-kinase inhibitor, also potently inhibits mammalian polo-like kinase. Chem Biol 2005, 12(1):99-107.

68. Nakamura M, Nakashima S, Katagiri Y, Nozawa Y: Effect of wortmannin and 2-(4-morpholinyl)-8-phenyl-4H-1-benzopyran-4-one (LY294002) on $\mathrm{N}$-formyl-methionyl-leucyl-phenylalanine-induced phospholipase $\mathrm{D}$ activation in differentiated HL60 cells: possible involvement of phosphatidylinositol 3-kinase in phospholipase D activation. Biochem Pharmacol 1997, 53(12):1929-1936.

69. Knight Z, et al: Chemically targeting the PI3K family. Biochem Soc Trans 2007, 35(Pt 2):245-249.

70. Marone R, et al: Targeting phosphoinositide 3-kinase: moving towards therapy. Biochim Biophys Acta 2008, 1784(1):159-185. 
71. Lannutti $B$, et al: CAL-101, a p110delta selective phosphatidylinositol-3kinase inhibitor for the treatment of B-cell malignancies, inhibits PI3K signaling and cellular viability. Blood 2011, 117(2):591-594.

72. Herman SEM, Gordon AL, Wagner AJ, Heerema NA, Zhao W, Flynn JM, Jones J, Andritsos L, Puri KD, Lannutti BJ, et al: Phosphatidylinositol 3-kinase-delta inhibitor CAL-101 shows promising preclinical activity in chronic lymphocytic leukemia by antagonizing intrinsic and extrinsic cellular survival signals. Blood 2010, 116:2078-2088.

73. Hoellenriegel J, et al: The phosphoinositide 3'-kinase delta inhibitor, CAL-101, inhibits B-cell receptor signaling and chemokine networks in chronic lymphocytic leukemia. Blood 2011, 118(13):3603-3612.

74. Meadows S, et al: PI3Kdelta inhibitor, GS-1101 (CAL-101), attenuates pathway signaling, induces apoptosis, and overcomes signals from the microenvironment in cellular models of Hodgkin lymphoma. Blood 2012 119(8):1897-1900

75. Ikeda $\mathrm{H}$, et al: $\mathrm{PI} 3 \mathrm{~K} / \mathrm{p} 110\{$ delta\} is a novel therapeutic target in multiple myeloma. Blood 2010, 116(9):1460-1468.

76. Coutre S, et al: Phase I study of CAL-101, an isoform-selective inhibitor of phosphatidylinositol 3-kinase P110d, in patients with previously treated chronic lymphocytic leukemia. J Clin Oncol 2011, 29:6631.

77. Furman $\mathrm{R}$, et al: CAL-101, an isoformselective inhibitor of phosphatidylinositol 3-kinase P1108,demonstrates clinical activity and pharmacodynamic effects in patients with relapsed or refractory chronic lymphocytic leukemia. Blood, (ASH Annual Meeting Abstracts) 2010, 160(21):55.

78. Keating $\mathrm{M}$, et al: Therapeutic role of alemtuzumab (Campath-1H) in patients who have failed fludarabine: results of a large international study. Blood 2002, 99(10):3554-3561.

79. Lemery S, et al: U.S. Food and Drug Administration approval: ofatumumab for the treatment of patients with chronic lymphocytic leukemia refractory to fludarabine and alemtuzumab. Clin Cancer Res 2010, 16(17):4331-4338.

80. Kahl B, et al: Clinical safety and activity in a phase 1 study of CAL-101, an isoform-selective inhibitor of phosphatidylinositol 3-kinase P110\{delta\}, in patients with relapsed or refractory non-Hodgkin lymphoma. ASH Annual Meeting Abstracts 2010, 116(21):1777.

81. Goy A, et al: Single-agent lenalidomide in patients with mantle-cell lymphoma who relapsed or progressed after or were refractory to Bortezomib: Phase II MCL-001 (EMERGE) study. J Clin Oncol 2013, 31:3688-3695.

82. Kane $\mathrm{R}$, et al: Bortezomib for the treatment of mantle cell lymphoma. Clin Cancer Res 2007, 13(18 Pt 1):5291-5294.

83. Coutre $S$, et al: Combinations of the Selective Phosphatidylinositol 3-Kinase-Delta (PI3Kdelta) Inhibitor GS-1101 (CAL-101) with Rituximab and/or Bendamustine Are Tolerable and Highly Active in Patients with Relapsed or Refractory Chronic Lymphocytic Leukemia (CLL): Results From a Phase I Study. Blood 2012, 120:ASH Abstract No.191.

84. Fischer $\mathrm{K}$, et al: Bendamustine combined with rituximab in patients with relapsed and/or refractory chronic lymphocytic leukemia: a multicenter phase II trial of the German Chronic Lymphocytic Leukemia Study Group. J Clin Oncol 2011, 29(26):3559-3566.

85. Bergmann $M$, et al: Efficacy of bendamustine in patients with relapsed or refractory chronic lymphocytic leukemia: results of a phase I/II study of the German CLL Study Group. Haematologica 2005, 90(10):1357-1364.

86. Furman $\mathrm{R}$, et al: $\mathrm{A}$ phase $\mathrm{I} / \mathrm{I}$ study of the selective phosphatidylinositol 3-kinase-delta (PI3K $\delta$ ) inhibitor, GS-1101 (CAL-101), with ofatumumab in patients with previously treated chronic lymphocytic leukemia(CLL). J Clin Oncol 2012, 30:6518.

87. Wierda W, et al: Ofatumumab as single-agent CD20 immunotherapy in fludarabine-refractory chronic lymphocytic leukemia. J Clin Oncol 2010, 28(10):1749-1755.

88. Eradat $\mathrm{H}$, et al: A phase III, randomized, double-blind, placebo-controlled study evaluating the efficacy and safety of idelalisib (GS-1101) in combination with bendamustine and rituximab for previously treated chronic lymphocytic leukemia (CLL). J Clin Oncol 2013, 31:TPS7133.

89. Flinn I, 2013, et al: A phase III, randomized, controlled study evaluating the efficacy and safety of idelalisib (GS-1101) in combination with ofatumumab for previously treated chronic lymphocytic leukemia (CLL). J Clin Oncol 2013, 31:TPS7131.

90. Leonard J, et al: Tolerability and activity of combinations of the PI3K $\delta$ inhibitor idelalisib (GS-1101) with rituximab and/or bendamustine in patients with previously treated, indolent non-Hodgkin lymphoma (iNHL): Updated results from a phase I study. J Clin Oncol 2013, 31:8500.
91. Rummel $M$, et al: Bendamustine plus rituximab is effective and has a favorable toxicity profile in the treatment of mantle cell and low-grade non-Hodgkin's lymphoma. J Clin Oncol 2005, 23(15):3383-3389.

92. De Vos S, et al: A phase III, randomized, double-blind, placebo-controlled study evaluating the efficacy and safety of idelalisib (GS-1101) in combination with bendamustine and rituximab for previously treated indolent non-Hodgkin lymphomas (iNHL). ASCO Meeting Abstracts 2013, 31(15):TPS8618.

93. Leonard J, et al: A phase III, randomized, double-blind, placebo-controlled study evaluating the efficacy and safety of idelalisib (GS-1101) in combination with rituximab for previously treated indolent non-Hodgkin lymphomas (iNHL). J Clin Oncol 2013, 31:TPS8617.

94. Wagner-Johnston $\mathrm{N}$, et al: Preliminary results of PI3K $\delta$ inhibitor idelalisib (GS-1101) treatment in combination with everolimus, bortezomib, or bendamustine/rituximab in patients with previously treated mantle cell lymphoma (MCL). J Clin Oncol 2013, 31:8501.

95. Robinson $\mathrm{K}$, et al: Phase II multicenter study of bendamustine plus rituximab in patients with relapsed indolent B-cell and mantle cell non-Hodgkin's lymphoma. J Clin Oncol 2008, 26(27):4473-4479.

96. Burger J, et al: Randomized, multicenter, open-label, phase III study of the BTK inhibitor ibrutinib versus chlorambucil in patients 65 years or older with treatment-naive CLL/SLL (RESONATE-2, PCYC-1115-CA). J Clin Oncol 2013, 31:TPS7130.

97. Dartigeas C, et al: Safety and Efficacy of Abbreviated Induction with Oral Fludarabine (F) and Cyclophosphamide (C) Combined with Dose-Dense IV Rituximab (R) in Previously Untreated Patients with Chronic Lymphocytic Leukemia (CLL) Aged > 65 years : Results of a Multicenter Trial (LLC 2007 SA) On Behalf of the French Goelams/Fcgcll-WM Intergroup. Blood 2012, 120:434.

98. Mulligan S, et al: A Randomised Dose De-Escalation Safety Study of Oral Fludarabine, \pm Oral Cyclophosphamide and Intravenous Rituximab (OFOCIR) As First-Line Therapy of Fit Patients with Chronic Lymphocytic Leukaemia (CLL) Aged $\geq 65$ Years - End of Recruitment Analysis of Response and Toxicity of the Australasian Leukaemia and Lymphoma Group (ALLG) and CLL Australian Research Consortium (CLLARC) CLL5 Study. Blood 2012, 120:436

99. Burger M, et al: Identification of NVP-BKM120 as a Potent, Selective, Orally Bioavailable Class I PI3 Kinase Inhibitor for Treating Cancer. ACS Med Chem Lett 2011, 2(10):774-779.

100. Zheng Y, et al: Novel phosphatidylinositol 3-kinase inhibitor NVP-BKM120 induces apoptosis in myeloma cells and shows synergistic anti-myeloma activity with dexamethasone. J Mol Med (Berl) 2012, 90(6):695-706.

101. Meier F, et al: The PI3K inhibitor BKM120 has potent antitumor activity in melanoma brain metastases in vitro and in vivo. ASCO Meeting Abstracts 2013, 31(15):e20050.

102. Bradford $\mathrm{L}$, et al: Targeting the PI3K signaling cascade in PIK3CA mutated endometrial cancer in a primary human xenograft model. ASCO Meeting Abstracts 2013, 31(15):e13564

103. Bendell J, et al: Phase I, Dose-Escalation Study of BKM120, an Oral Pan-Class I PI3K Inhibitor, in Patients With Advanced Solid Tumors. J Clin Oncol 2012, 30(3):282-290.

104. Chakravarti A, et al: The prognostic significance of phosphatidylinositol 3-kinase pathway activation in human gliomas. J Clin Oncol 2004, 22(10):1926-1933.

105. Shih $\mathrm{K}$, et al: Phase I study of the combination of BKM120 and bevacizumab in patients with relapsed/refractory glioblastoma multiforme (GBM) or other refractory solid tumors. ASCO Meeting Abstracts 2013, 31(15):e13045

106. Wen $\mathrm{P}$, et al: Phase II trial of the phosphatidyinositol-3 kinase (PI3K) inhibitor BKM120 in recurrent glioblastoma (GBM). ASCO Meeting Abstracts 2013, 31(15):2015.

107. Mayer l, et al: SU2C phase lb study of pan-PI3K inhibitor BKM120 with letrozole in ER+/HER2- metastatic breast cancer (MBC). J Clin Oncol 2012, 30:510.

108. Iwata $\mathrm{H}$, et al: $\mathrm{Ph}$ III randomized studies of the oral pan-PI3K inhibitor buparlisib (BKM120) with fulvestrant in postmenopausal women with HR+/HER2- locally advanced or metastatic breast cancer (BC) after aromatase inhibitor (Al; BELLE-2) or Al and mTOR inhibitor (BELLE-3) treatment. ASCO Meeting Abstracts 2013, 31(15):TPS650.

109. Tan D, et al: A phase Ib safety and tolerability study of a pan class I PI3K inhibitor buparlisib (BKM120) and gefitinib (gef) in EGFR TKI-resistant NSCLC. J Clin Oncol 2013, 31:8107. 
110. Folkes $\mathrm{A}$, et al: The identification of 2-(1H-indazol-4-yl)-6-(4-methanesulfonylpiperazin-1-ylmethyl)-4-morpholin-4-yl-t hieno[3,2-d]pyrimidine (GDC-0941) as a potent, selective, orally bioavailable inhibitor of class I PI3 kinase for the treatment of cancer. J Med Chem 2008, 51(18):5522-5532.

111. Junttila T, et al: Ligand-independent HER2/HER3/PI3K complex is disrupted by trastuzumab and is effectively inhibited by the PI3K inhibitor GDC-0941. Cancer Cell 2009, 15(5):429-440.

112. Garcia-Martinez J, et al: Effect of PI3K- and mTOR-specific inhibitors on spontaneous B-cell follicular lymphomas in PTEN/LKB1-deficient mice. Br J Cancer 2011, 104(7):1116-1125.

113. Yao E, et al: Suppression of HER2/HER3-Mediated Growth of Breast Cancer Cells with Combinations of GDC-0941 PI3K Inhibitor, Trastuzumab, and Pertuzumab. Clin Cancer Res 2009, 15(12):4147-4156.

114. Zou ZQ, Zhang LN, Wang F, Bellenger J, Shen YZ, Zhang XH: The novel dual PI3K/mTOR inhibitor GDC-0941 synergizes with the MEK inhibitor U0126 in non-small cell lung cancer cells. Molec Med Rep 2012, 5(2):503-508.

115. Li H, Wozniak A, Van Den Bossche K, Van Looy T, Wellens J, Stas M, Floris G, Friedman L, Debiec-Rychter M, Sciot R, et al: Efficacy of the phosphoinositol 3 kinase (PI3K) inhibitor GDC-0941 in patient- and cell-line-derived xenografts of dedifferentiated liposarcoma (DDLPS). ASCO Meeting Abstracts 2013, 31(15):e13528

116. Floris G, Wozniak A, Sciot R, Li H, Friedman L, Van Looy T, Wellens J, Vermaelen P, Deroose CM, Fletcher JA, et al: A Potent Combination of the Novel PI3K Inhibitor, GDC-0941, with Imatinib in Gastrointestinal Stromal Tumor Xenografts: Long-Lasting Responses after Treatment Withdrawal. Clin Cancer Res 2013, 19(3):620-630.

117. Wagner $A$, et al: A first-in-human phase I study to evaluate the pan-PI3K inhibitor GDC-0941 administered QD or BID in patients with advanced solid tumors. J Clin Oncol 2009, 27:3501. ASCO Annual Meeting Proceedings.

118. Von Hoff D, et al: A phase I dose-escalation study to evaluate GDC-0941, a pan-PI3K inhibitor, administered QD or BID in patients with advanced or metastatic solid tumors. J Clin Oncol 2011, 29:3052.

119. Garcia $V$, et al: A phase I study evaluating GDC-0941, an oral phosphoinositide-3 kinase (PI3K) inhibitor, in patients with advanced solid tumors or multiple myeloma. J Clin Oncol 2011, 29:3021.

120. Baird R, et al: A phase I study evaluating the pharmacokinetics (PK) and pharmacodynamics (PD) of the oral pan-phosphoinositide-3 kinase (PI3K) inhibitor GDC-0941. J Clin Oncol (Meeting Abstracts) 2010, 28(15):2613.

121. LoRusso $P$, et al: $A$ first-in-human phase $\mathrm{lb}$ study to evaluate the MEK inhibitor GDC-0973, combined with the pan-PI3K inhibitor GDC-0941, in patients with advanced solid tumors. J Clin Oncol 2012, 30:2566.

122. Shapiro G: Clinical combination of the MEK inhibitor GDC-0973 and the PI3K inhibitor GDC-0941: A first-in-human phase lb study testing daily and intermittent dosing schedules in patients with advanced solid tumors. J Clin Oncol 2011, 29:3005.

123. Besse B, et al: A phase lb study to evaluate the PI3-kinase inhibitor GDC-0941 with paclitaxel $(P)$ and carboplatin $(C)$, with and without bevacizumab (BEV), in patients with advanced non-small cell lung cancer (NSCLC). J Clin Oncol 2011, 29:3044.

124. Ihle NT, Paine-Murrieta G, Berggren MI, Baker A, Tate WR, Wipf P, Abraham RT, Kirkpatrick DL, Powis G: The phosphatidylinositol-3-kinase inhibitor PX-866 overcomes resistance to the epidermal growth factor receptor inhibitor gefitinib in A-549 human non-small cell lung cancer xenografts. Mol Cancer Ther 2005, 4(9):1349-1357.

125. Ihle NT, Williams R, Chow S, Chew W, Berggren MI, Paine-Murrieta G, Minion DJ, Halter RJ, Wipf P, Abraham R, et al: Molecular pharmacology and antitumor activity of PX-866, a novel inhibitor of phosphoinositide-3-kinase signaling. Mol Cancer Ther 2004, 3(7):763-772.

126. Jimeno A, et al: Final results from a phase I, dose-escalation study of PX-866, an irreversible, pan-isoform inhibitor of PI3 kinase. J Clin Oncol 2010, 28(15s):3089.

127. Jimeno A, et al: PX-866 and docetaxel in patients with advanced solid tumors. J Clin Oncol 2012, 30:3024.

128. Pitz MW, Eisenhauer EA, MacNeil MV, Thiessen B, Macdonald DR, Easaw JC, Eisenstat DD, Kakumanu AS, Squire J, Tsao MS, et al: Phase II study of PX-866 in recurrent glioblastoma. ASCO Meeting Abstracts 2013, 31(15):2053.
129. Hotte SJ, Eisenhauer EA, Joshua AM, Kumar V, Ellard S, Gregg RW, Macfarlane RJ, Winquist E, Torri V, Ruether JD, et al: NCIC CTG, IND-205: A phase II study of PX-866 in patients with recurrent or metastatic castration-resistant prostate cancer (CRPC). ASCO Meeting Abstracts 2013, 31(15):5042.

130. Ndubaku CO, Heffron TP, Staben ST, Baumgardner M, Blaquiere N, Bradley E, Bull R, Do S, Dotson J, Dudley D, et al: Discovery of 2-\{3-[2-(1-isopropyl-3-methyl-1H-1,2-4-triazol-5-yl)-5,6-dihydrobenzo[f]imidazo[1,2-d][1,4]oxazepin9-yl]-1H-pyrazol-1-yl\}-2-methylpropanamide (GDC-0032): a beta-sparing phosphoinositide 3-kinase inhibitor with high unbound exposure and robust in vivo antitumor activity. J Med Chem 2013, 56(11):4597-4610.

131. Staben ST, Ndubaku C, Blaquiere N, Belvin M, Bull RJ, Dudley D, Edgar K, Gray D, Heald R, Heffron TP, et al: Discovery of thiazolobenzoxepin PI3-kinase inhibitors that spare the PI3-kinase beta isoform. Bioorg Med Chem Lett 2013, 23(9):2606-2613.

132. Juric D, et al: GDC-0032, a Beta Isoform-Sparing PI3K Inhibitor: Results of a First-in-Human Phase 1a Dose Escalation Study. Cancer Res (AACR Annual Meeting abstracts) 2013, 73:LB-64.

133. Liu N, Rowley BR, Bull CO, Schneider C, Haegebarth A, Schatz CA, Fracasso PR, Wilkie DP, Hentemann M, Wilhelm SM, et al: BAY 80-6946 Is a Highly Selective Intravenous PI3K Inhibitor with Potent p110alpha and p110delta Activities in Tumor Cell Lines and Xenograft Models. Mol Cancer Ther 2013, 12(11):2319-2330.

134. Jeffers M, et al: Evaluation of the PI3K inhibitor BAY 80-6946 in hematologic malignancies. J Clin Oncol 2012, 30:e13576.

135. Patnaik A, Ramanathan RK, Appleman $\sqcup$, Tolcher AW, Mountz JM, Beerham M, Weiss GJ, Rasco DW, Lotze MT, Toledo FG, et al: Phase I Study of Intravenous PI3K Inhibitor Bay 80-6946: Preliminary Activity in Patients with Relapsed Non-Hodgkin Lymphoma (NHL) Treated in an MTD Expansion Cohort. ASH Annual Meeting Abstracts 2012, 120(21):3704.

136. Patnaik $A$, et al: A first-in-human phase I study of intravenous PI3K inhibitor BAY 80-6946 in patients with advanced solid tumors: Results of dose-escalation phase. J Clin Oncol 2011, 29:3035.

137. Lotze $M$, et al: Phase I study of intravenous PI3K inhibitor BAY 80-6946: Activity in patients (pts) with advanced solid tumors and non-Hodgkin lymphoma treated in MTD expansion cohorts. J Clin Oncol 2012, 30:3019.

138. Dunbar J, et al: Pharmacokinetics and Pharmacodynamics of IPI-145, a Potent Inhibitor of Phosphoinositide-3-Kinase-\{delta\},\{gamma\}, Following Single- and Multiple-Dose Administration in Healthy Subjects and Patients with Advanced Hematologic Malignancies. Blood (ASH Annual Meeting Abstracts) 2012, 120:4853.

139. Flinn I, et al: Clinical Safety and Activity in a Phase 1 Trial of IPI-145, a Potent Inhibitor of Phosphoinositide-3-Kinase-\{delta\},\{gamma\}, in Patients with Advanced Hematologic Malignancies. Blood (ASH Annual Meeting Abstracts) 2012, 120:3663

140. Maira SM, Stauffer F, Brueggen J, Furet P, Schnell C, Fritsch C, Brachmann S, Chene $P$, De Pover A, Schoemaker $K$, et al: Identification and characterization of NVP-BEZ235, a new orally available dual phosphatidylinositol 3-kinase/ mammalian target of rapamycin inhibitor with potent in vivo antitumor activity. Mol Cancer Ther 2008, 7(7):1851-1863.

141. Serra V, Markman B, Scaltriti M, Eichhorn PJ, Valero V, Guzman M, Botero ML, Llonch E, Atzori F, Di Cosimo S, et al: NVP-BEZ235, a dual PI3K/mTOR inhibitor, prevents $\mathrm{PI} 3 \mathrm{~K}$ signaling and inhibits the growth of cancer cells with activating PI3K mutations. Cancer Res 2008, 68(19):8022-8030.

142. Schnell CR, Stauffer F, Allegrini PR, O'Reilly T, McSheehy PM, Dartois C, Stumm M, Cozens R, Littlewood-Evans A, Garcia-Echeverria C, et al: Effects of the dual phosphatidylinositol 3-kinase/mammalian target of rapamycin inhibitor NVP-BEZ235 on the tumor vasculature: implications for clinical imaging. Cancer Res 2008, 68(16):6598-6607.

143. Eichhorn PJ, Gili M, Scaltriti M, Serra V, Guzman M, Nijkamp W, Beijersbergen RL, Valero V, Seoane J, Bernards R, et al: Phosphatidylinositol 3-kinase hyperactivation results in lapatinib resistance that is reversed by the mTOR/phosphatidylinositol 3-kinase inhibitor NVP-BEZ235. Cancer Res 2008, 68(22):9221-9230.

144. Cao P, Maira SM, Garcia-Echeverria C, Hedley DW: Activity of a novel, dual PI3-kinase/mTor inhibitor NVP-BEZ235 against primary human pancreatic cancers grown as orthotopic xenografts. Br J Cancer 2009, 100(8):1267-1276

145. Liu TJ, Koul D, LaFortune T, Tiao N, Shen RJ, Maira SM, Garcia-Echevrria C, Yung WK: NVP-BEZ235, a novel dual phosphatidylinositol 3-kinase/mammalian target of rapamycin inhibitor, elicits multifaceted antitumor activities in human gliomas. Mol Cancer Ther 2009, 8(8):2204-2210. 
146. Manara MC, Nicoletti G, Zambelli D, Ventura S, Guerzoni C, Landuzzi L, Lollini PL, Maira SM, Garcia-Echeverria C, Mercuri M, et al: NVP-BEZ235 as a new therapeutic option for sarcomas. Clin Canc Res 2010, 16(2):530-540.

147. Cho DC, Cohen MB, Panka DJ, Collins M, Ghebremichael M, Atkins MB, Signoretti S, Mier JW: The efficacy of the novel dual PI3-kinase/mTOR inhibitor NVP-BEZ235 compared with rapamycin in renal cell carcinoma. Clin Canc Res 2010, 16(14):3628-3638.

148. Santiskulvong C, Konecny GE, Fekete M, Chen KY, Karam A, Mulholland D, Eng $C$, Wu H, Song M, Dorigo O: Dual targeting of phosphoinositide 3-kinase and mammalian target of rapamycin using NVP-BEZ235 as a novel therapeutic approach in human ovarian carcinoma. Clin Canc Res 2011, 17(8):2373-2384.

149. Arkenau $\mathrm{H}$, et al: The PI3K/mTOR inhibitor BEZ235 given twice daily for the treatment of patients (pts) with advanced solid tumors. J Clin Oncol 2012, 30:3097.

150. Krop I, et al: A phase I/IB dose-escalation study of BEZ235 in combination with trastuzumab in patients with PI3-kinase or PTEN altered HER2+ metastatic breast cancer. J Clin Oncol 2012, 30:508.

151. Salkeni $M$, et al: A dose escalation, single arm, phase $\mathrm{lb} / \mathrm{ll}$ combination study of BEZ235 with everolimus to determine the safety, pharmacodynamics, and pharmacokinetics in subjects with advanced solid malignancies including glioblastoma multiforme. J Clin Oncol 2012 30:TPS3116.

152. Salkeni M, et al: BEZ235 in combination with everolimus for advanced solid malignancies: Preliminary results of a phase $\mathrm{lb}$ dose-escalation study. J Clin Oncol 2013, 31:e13518.

153. Juric D, et al: BYL719, a next generation PI3K alpha specific inhibitor: Preliminary safety, PK, and efficacy results from the first-in-human study. Cancer Res 2012, 72(8):1.

154. Cao Z, et al: Targeting PIK3CA mutant breast cancer with the combination of PIK3CA-specific inhibitor, BYL719, and IGF1-R antibody, ganitumab. J Clin Oncol 2013, 31:e13525.

155. Gonzalez-Angulo A, et al: Safety, pharmacokinetics, and preliminary activity of the a-specific PI3K inhibitor BYL719: Results from the first-in-human study. J Clin Oncol 2013, 31:2531.

156. Markman B, Tabernero J, Krop I, Shapiro Gl, Siu L, Chen LC, Mita M Melendez Cuero M, Stutvoet S, Birle D, et al: Phase I safety, pharmacokinetic, and pharmacodynamic study of the oral phosphatidylinositol-3-kinase and mTOR inhibitor BGT226 in patients with advanced solid tumors. Ann Oncol 2012, 23(9):2399-2408.

157. Chang KY, Tsai SY, Wu CM, Yen CJ, Chuang BF, Chang JY: Novel phosphoinositide 3-kinase/mTOR dual inhibitor, NVP-BGT226, displays potent growth-inhibitory activity against human head and neck cancer cells in vitro and in vivo. Clin Canc Res 2011, 17(22):7116-7126.

158. Baumann P, Schneider L, Mandl-Weber S, Oduncu F, Schmidmaier R: Simultaneous targeting of PI3K and mTOR with NVP-BGT226 is highly effective in multiple myeloma. Anti Canc Drugs 2012, 23(1):131-138.

159. Glienke W, Maute L, Wicht J, Bergmann L: The dual PI3K/mTOR inhibitor NVP-BGT226 induces cell cycle arrest and regulates Survivin gene expression in human pancreatic cancer cell lines. Tumour Biol 2012, 33(3):757-765.

160. Yuan J, Mehta PP, Yin MJ, Sun S, Zou A, Chen J, Rafidi K, Feng Z, Nickel J, Engebretsen J, et al: PF-04691502, a potent and selective oral inhibitor of PI3K and mTOR kinases with antitumor activity. Mol Cancer Ther 2011, 10(11):2189-2199

161. Kinross KM, Brown DV, Kleinschmidt M, Jackson S, Christensen J, Cullinane C, Hicks RJ, Johnstone RW, McArthur GA: In vivo activity of combined PI3K/mTOR and MEK inhibition in a Kras(G12D);Pten deletion mouse model of ovarian cancer. Mol Cancer Ther 2011, 10(8):1440-1449.

162. Millham R, et al: First-in-patient study of PF-04691502, a small molecule intravenous dual inhibitor of PI3K and mTOR in patients with advanced cancer: Update on safety, efficacy, and pharmacology. Mol Cancer Ther 2011, 10(1):11.

163. Sutherlin DP, Bao L, Berry M, Castanedo G, Chuckowree I, Dotson J, Folks A, Friedman L, Goldsmith R, Gunzner J, et al: Discovery of a potent, selective, and orally available class I phosphatidylinositol 3-kinase (PI3K)/mammalian target of rapamycin (mTOR) kinase inhibitor (GDC-0980) for the treatment of cancer. J Med Chem 2011, 54(21):7579-7587.

164. Wallin JJ, Edgar KA, Guan J, Berry M, Prior WW, Lee L, Lesnick JD, Lewis C, Nonomiya J, Pang J, et al: GDC-0980 is a novel class I PI3K/mTOR kinase inhibitor with robust activity in cancer models driven by the PI3K pathway. Mol Cancer Ther 2011, 10(12):2426-2436.
165. Salphati L, Pang J, Plise EG, Lee LB, Olivero AG, Prior WW, Sampath D, Wong S, Zhang $X$ : Preclinical assessment of the absorption and disposition of the phosphatidylinositol 3-kinase/mammalian target of rapamycin inhibitor GDC-0980 and prediction of its pharmacokinetics and efficacy in human. Drug Metabol Dispos: The Biological Fate of Chemicals 2012, 40(9):1785-1796.

166. Dey N, et al: A combination of dual PI3K-mTOR inhibitor, GDC-0980, with PARP inhibitor plus carboplatin blocked tumor growth of BRCAcompetent triple-negative breast cancer cells. J Clin Oncol 2013, 31:2613.

167. Wagner AJ, et al: A first-in-human phase I study to evaluate GDC-0980, an oral $\mathrm{PI} 3 \mathrm{~K} / \mathrm{mTOR}$ inhibitor, administered $\mathrm{QD}$ in patients with advanced solid tumors. J Clin Oncol 2011, 29:3020.

168. Funke $\mathrm{R}$, et al: A phase $\mathrm{Ib} / \mathrm{ll}$ study testing the safety and efficacy of combined inhibition of the AKT/PI3K and AR signaling pathways in castration-resistant prostate cancer: GDC-0068 or GDC-0980 with abiraterone acetate versus abiraterone acetate. J Clin Oncol 2012, 30:TPS2616.

169. Knight S, et al: Discovery of GSK2126458, a Highly Potent Inhibitor of PI3K and the Mammalian Target of Rapamycin. ACS Med Chem Lett 2010, 1(1):39-43.

170. Munster P, et al: Phase I first-in-human study of the PI3 kinase inhibitor GSK2126458 (GSK458) in patients with advanced solid tumors (study P3K112826). J Clin Oncol 2011, 29:3018.

171. Venkatesan AM, Dehnhardt CM, Delos Santos E, Chen Z, Dos Santos O, Ayral-Kaloustian S, Khafizova G, Brooijmans N, Mallon R, Hollander I, et al: Bis (morpholino-1,3,5-triazine) derivatives: potent adenosine 5'-triphosphate competitive phosphatidylinositol-3-kinase/mammalian target of rapamycin inhibitors: discovery of compound 26 (PKI-587), a highly efficacious dual inhibitor. J Med Chem 2010, 53(6):2636-2645.

172. Millham R, et al: First-in-patient study of PF-05212384, a small molecule intravenous dual inhibitor of PI3K and mTOR in patients with advanced cancer: Update on safety, efficacy, and pharmacology. Mol Cancer Ther 2011, 10(11):1

173. Garcia-Echeverria C, Sellers WR: Drug discovery approaches targeting the PI3K/Akt pathway in cancer. Oncogene 2008, 27(41):5511-5526.

174. Mirzoeva OK, Hann B, Hom YK, Debnath J, Aftab D, Shokat K, Korn WM: Autophagy suppression promotes apoptotic cell death in response to inhibition of the PI3K-mTOR pathway in pancreatic adenocarcinoma. J Mol Med (Berl) 2011, 89(9):877-889.

175. Prasad G, Sottero T, Yang X, Mueller S, James CD, Weiss WA, Polley MY, Ozawa T, Berger MS, Aftab DT, et al: Inhibition of PI3K/mTOR pathways in glioblastoma and implications for combination therapy with temozolomide. Neuro Oncol 2011, 13(4):384-392.

176. LoRusso $P$, et al: A phase I dose-escalation study of the safety, pharmacokinetics (PK), and pharmacodynamics of XL765, a PI3K/TORC1/TORC2 inhibitor administered orally to patients (pts) with advanced solid tumors. J Clin Oncol 2009, 27(15s):3502.

177. Cohen $\mathrm{R}$, et al: A phase I safety and pharmacokinetic (PK) study of PI3K/TORC1/TORC2 inhibitor XL765 (SAR245409) in combination with erlotinib (E) in patients (pts) with advanced solid tumors. J Clin Oncol 2010, 28(15s):3015.

178. Nghiemphu P, et al: A phase I safety and pharmacokinetic study of XL765 (SAR245409), a novel PI3K/TORC1/TORC2 inhibitor, in combination with temozolomide (TMZ) in patients (pts) with newly diagnosed malignant glioma. J Clin Oncol 2010, 28(15s):3085.

179. Chakrabarty A, Sanchez V, Kuba MG, Rinehart C, Arteaga CL: Feedback upregulation of HER3 (ErbB3) expression and activity attenuates antitumor effect of PI3K inhibitors. Proc Natl Acad Sci U S A 2012, 109(8):2718-2723.

180. Edelman $\mathrm{G}$, et al: A phase I dose-escalation study of XL147 (SAR245408), a PI3K inhibitor administered orally to patients (pts) with advanced malignancies. J Clin Oncol 2010, 28(15s):3004.

181. Moldovan C, et al: A phase I safety and pharmacokinetic (PK) study of the PI3K inhibitor XL147 (SAR245408) in combination with erlotinib in patients (pts) with advanced solid tumors. J Clin Oncol 2010, 28(15s):3070.

182. Traynor A, et al: A phase I safety and pharmacokinetic (PK) study of the PI3K inhibitor XL147 (SAR245408) in combination with paclitaxel (P) and carboplatin (C) in patients (pts) with advanced solid tumors. J Clin Oncol 2010, 28(15s):3078.

183. Cloughesy $T$, et al: Tumor pharmacokinetics (PK) and pharmacodynamics (PD) of SAR245409 (XL765) and SAR245408 (XL147) administered as single agents to patients with recurrent glioblastoma (GBM): An Ivy Foundation early-phase clinical trials consortium study. $J$ Clin Oncol 2013, 31:2012. 
184. Firer M, Gellerman G: Targeted drug delivery for cancer therapy: the other side of antibodies. J Hematol Oncol 2012, 5(1):70.

185. Huang T, Karsy M, Zhuge J, Zhong M, Liu D: B-Raf and the inhibitors: from bench to bedside. J Hematol Oncol 2013, 6(1):30.

186. Wang K, Wei G, Liu D: CD19: a biomarker for B cell development, lymphoma diagnosis and therapy. Exp Hematol Oncol 2012, 1(1):36.

187. Lamba G, Ambrale S, Lee B, Gupta R, Rafiyath S, Liu D: Recent advances and novel agents for gastrointestinal stromal tumor (GIST). J Hematol Oncol 2012, 5(1):21.

188. Lee B, Mukhi N, Liu D: Current management and novel agents for malignant melanoma. J Hematol Oncol 2012, 5(1):3.

189. Cang S, Mukhi N, Wang K, Liu D: Novel CD20 monoclonal antibodies for lymphoma therapy. J Hematol Oncol 2012, 5:64.

\section{doi:10.1186/1756-8722-6-88}

Cite this article as: Akinleye et al:: Phosphatidylinositol 3-kinase (PI3K) inhibitors as cancer therapeutics. Journal of Hematology \& Oncology 2013 6:88.

\section{Submit your next manuscript to BioMed Central and take full advantage of:}

- Convenient online submission

- Thorough peer review

- No space constraints or color figure charges

- Immediate publication on acceptance

- Inclusion in PubMed, CAS, Scopus and Google Scholar

- Research which is freely available for redistribution 